\title{
Delamination buckling and postbuckling in composite cylindrical shells under external pressure
}

DOI:

10.1016/j.tws.2004.05.008

\section{Document Version}

Accepted author manuscript

Link to publication record in Manchester Research Explorer

\section{Citation for published version (APA):}

Tafreshi, A. (2004). Delamination buckling and postbuckling in composite cylindrical shells under external pressure. Thin-Walled Structures, 42(10), 1379-1404. https://doi.org/10.1016/j.tws.2004.05.008

\section{Published in:}

Thin-Walled Structures

\section{Citing this paper}

Please note that where the full-text provided on Manchester Research Explorer is the Author Accepted Manuscript or Proof version this may differ from the final Published version. If citing, it is advised that you check and use the publisher's definitive version.

\section{General rights}

Copyright and moral rights for the publications made accessible in the Research Explorer are retained by the authors and/or other copyright owners and it is a condition of accessing publications that users recognise and abide by the legal requirements associated with these rights.

\section{Takedown policy}

If you believe that this document breaches copyright please refer to the University of Manchester's Takedown Procedures [http://man.ac.uk/04Y6Bo] or contact uml.scholarlycommunications@manchester.ac.uk providing relevant details, so we can investigate your claim.

\section{OPEN ACCESS}


Tafreshi, A. Oct 2004 In : Thin-Walled Structures. 42, 10, p. 1379-1404 26 p.

\title{
DELAMINATION BUCKLING AND POSTBUCKLING IN COMPOSITE CYLINDRICAL SHELLS UNDER EXTERNAL PRESSURE
}

\author{
Azam Tafreshi Aerospace Engineering, School of Engineering, \\ University of Manchester, Oxford Road, \\ Manchester M13 9PL, UK, atafreshi@manchetser.ac.uk
}

\begin{abstract}
Composite cylindrical shells and panels are widely used in aerospace structures. These are often subjected to defects and damage from both in-service and manufacturing events. Delamination is the most important of these defects. This paper deals with the computational modelling of delamination buckling and postbuckling of laminated composite cylindrical shells subjected to external pressure. The use of three-dimensional finite elements for predicting the delamination buckling and postbuckling of these structures is computationally expensive. Here the combined double-layer and single-layer of shell elements are employed to study the effect of delamination on the global loadcarrying capacity of such systems under external pressure. It is shown that through-thethickness delamination can be modelled and analysed effectively without requiring a great deal of computing time and memory. A parametric study is carried out to investigate the influence of the delamination size, orientation and through-the-thickness position of a series of laminated cylinders. The effects of material properties and stacking sequence are also investigated. Some of the results are compared with the corresponding analytical results. It is shown that ignoring the contact between the delaminated layers can result in wrong estimations of the critical buckling loads in cylindrical shells under external pressure.
\end{abstract}

Keywords: Delamination, composites, finite element method, buckling analysis, laminated cylindrical shells, external pressure 


\section{Nomenclature}

a

$\overline{\mathrm{a}}=\mathrm{a} / \mathrm{L}$

b

$\mathrm{E}_{11}, \mathrm{E}_{22}, \mathrm{G}_{12}, v_{12}$

$\mathrm{G}$

$\mathrm{t}_{1}, \mathrm{t}_{2}$

$\mathrm{h}=\mathrm{t}_{1} / \mathrm{t}$

$\mathrm{L}, \mathrm{R}, \mathrm{t}$

$\mathrm{X}, \mathrm{Y}, \mathrm{Z}$

$\mathrm{P}_{\mathrm{c}}$

$\mathrm{P}_{\mathrm{cr}}$

$\mathrm{u}\left(\right.$ or $\left.\mathrm{u}_{\mathrm{x}}\right), \mathrm{v}\left(\right.$ or $\left.\mathrm{u}_{\mathrm{y}}\right), \mathrm{w}\left(\right.$ or $\left.\mathrm{u}_{\mathrm{z}}\right)$

$\mathrm{x}, \mathrm{y}, \mathrm{z}$

$\psi_{\mathrm{x}}, \psi_{\mathrm{y}}, \psi_{\mathrm{z}}$

$\alpha$ length of delamination

normalized delamination length

delamination width, $(b=\mathrm{R} \alpha)$

material constants

strain energy release rate

thicknesses of upper and lower sublaminates, respectively

normalized delamination thickness

length, radius and thickness of the overall cylindrical shell, respectively

nodal force components in the $\mathrm{x}, \mathrm{y}$ and $\mathrm{z}$ directions, respectively

critical buckling load of an intact cylinder

critical buckling load of a delaminated cylinder

axial, circumferential and radial displacements, respectively

axial, circumferential and radial coordinates, respectively

rotation about the $\mathrm{y}, \mathrm{x}$, and $\mathrm{z}$ axes, respectively

angle of the delamination region (delamination width)

\section{INTRODUCTION}

Laminated composites are gaining importance in aircraft structural applications as a result of their very high strength-to-weight and high stiffness-to-weight ratios. It is known that delaminations are the most frequent causes of failure in laminated structures, particularly under compressive load and external pressure. Delaminations in composite materials result typically from impact damage or manufacturing imperfections. The presence of delaminations leads to a reduction in the overall buckling strength of the structure. In addition, delaminations tend to grow rapidly under postbuckling loads, causing further reduction in structural strength and leading ultimately to fatal structural failure. 
The phenomenon of progressive failure in laminated composite structures is yet to be understood, and as a result, reliable strategies for designing optimal composite structures for desired life and strength are in progress [1,2].

For the past two decades analytical and numerical analyses have been carried out by many researchers to analyse delaminated composite structures, considering their buckling and post-buckling behaviour. Almost all of the papers on delamination buckling deal with beams and flat plates [3-10]. The early work belongs to Chai et al. [11] who characterized the delamination buckling models by the delamination thickness and the number of delaminations through the laminate thickness.

In a recent study by the author [12] finite element models were developed to study global, local and mixed mode buckling behaviour of composite flat plates with embedded delamination under compression. The results were in agreement with the corresponding experimental results. In comparison with the other numerical models, it was shown that embedded delaminations can be modelled and analysed effectively without requiring a great deal of computing time and capacity.

There has been a reasonable amount of work on buckling and post-buckling behaviour of cylindrical shells and panels under axial compression and external pressure [13-24]. Due to its mathematical complexity and modelling, very limited information on the subject of delamination buckling of cylindrical shells and panels is currently available [25-35]. The most comprehensive study is by Simitses et al [27]. Simitses et al [26-27] analytically predicted delamination buckling of cylindrical shells and panels. The load cases considered in their study were uniform axial compression and uniform external pressure, applied individually. In order to ease the mathematical modelling, they kept the models as simple as possible. For example, in the axial compression case, the delamination extended along the entire circumference of the cylindrical shell. In the case of external pressure, cylindrical shells and panels with longitudinal delamination over the entire length were considered. For both cases they did not account for the contact between delaminated layers during buckling. 
This paper numerically studies the effect of delamination on the global load-carrying capacity of laminated cylindrical shells under external pressure, where the effect of contact between the delaminated layers is considered. The use of three-dimensional finite elements for the modelling of delamination in cylindrical shells is computationally expensive. In the present study an efficient modelling approach is employed for investigation of buckling and postbuckling behaviour of these structures. This requires less computing time and space for the same level of accuracy. Some parametric studies are performed to investigate the influence of the delamination size, orientation and through-the-thickness position on the critical loads of a series of delaminated cylindrical shells. The effects of the material properties and stacking sequence of laminated cylindrical shells are also investigated.

The analysis has been carried out using ABAQUS 6.3 which is available on the mainframe computer, Bezier, at Manchester Computing centre.

\section{BUCKLING AND POSTBUCKLING ANALYSIS OF LAMINATED CYLINDRICAL SHELLS USING THE FINITE ELEMENT METHOD}

Fig. 1a shows the geometry of a typical cylindrical shell with a rectangular delamination $(\mathrm{a} \times \mathrm{b})$ under external pressure, where the first measurement (a) is in the axial direction, the second measurement (b) is in the circumferential direction and $b=\mathrm{R} \alpha$. Angle $\alpha$ denotes the region of the delamination and $R$ is the radius of the cylinder. $t_{1}$ and $t_{2}$ are the thicknesses of the upper and lower sublaminates, respectively. The nondimensional parameter $\mathrm{h}=\mathrm{t}_{1} / \mathrm{t}$ is used to describe the delamination thickness, where $\mathrm{t}$ is the thickness of the cylinder.

A differential element of an intact cylindrical shell segment with the coordinate axes is shown in Fig. 2. The axial coordinate is $\mathrm{x}$, the circumferential coordinate is $\mathrm{y}$, and the thickness coordinate normal to the shell surface is $\mathrm{z}$. $\mathrm{R}$ is the radius of the cylindrical shell segment and the circumferential coordinate is replaced by $\mathrm{y}=\mathrm{R} \beta$. The displacement field 
for an intact cylindrical shell, according to a first-order, shear deformation theory is given by

$\mathrm{u}_{\mathrm{x}}=\mathrm{u}_{\mathrm{x}}^{0}+\mathrm{z} \psi_{\mathrm{x}}$

$\mathrm{u}_{\mathrm{y}}=\mathrm{u}_{\mathrm{y}}^{0}+\mathrm{z} \psi_{\mathrm{y}}$

$\mathrm{u}_{\mathrm{z}}=\mathrm{u}_{\mathrm{z}}^{0}$

$\mathrm{u}_{\mathrm{x}}, \mathrm{u}_{\mathrm{y}}, \mathrm{u}_{\mathrm{z}}$ are the displacements (in the $\mathrm{x}, \mathrm{y}$ and $\mathrm{z}$ directions, respectively) and $\psi_{\mathrm{x}}, \psi_{\mathrm{y}}$ are the rotations (about $\mathrm{y}$ and $\mathrm{x}$ axes, respectively), at arbitrary locations with the distance $\mathrm{z}$ to the shell's mid-surface. $\mathrm{u}_{\mathrm{x}}^{0}, \mathrm{u}_{\mathrm{y}}^{0}, \mathrm{u}_{\mathrm{z}}^{0}$ are the mid-surface displacements of the shell in the respective directions.

For the finite element analysis of a typical cylindrical shell or panel without delamination and under external pressure, a single layer of shell elements, designated S8R in ABAQUS, can be employed and the corresponding buckling and post-buckling analysis can be performed. It is also possible to model the entire laminate using two layers of shell elements forming an upper and lower sublaminate, where the nodes are located on the midsurfaces of the laminates. In order to enforce compatibility along the interface, constraint equations based on equations 1 can be imposed. The following constraint equations will tie the upper and lower sublaminates in both displacements and rotations along the interface so that both sublaminates together deform like an intact single laminate.

$$
\begin{aligned}
& \mathrm{u}_{\mathrm{x}}^{1,0}-\left(\frac{\mathrm{t}_{1}}{2}\right) \psi_{\mathrm{x}}^{1}=\mathrm{u}_{\mathrm{x}}^{2,0}+\left(\frac{\mathrm{t}_{2}}{2}\right) \psi_{\mathrm{x}}^{2} \\
& \mathrm{u}_{\mathrm{y}}^{1,0}-\left(\frac{\mathrm{t}_{1}}{2}\right) \psi_{\mathrm{y}}^{1}=\mathrm{u}_{\mathrm{y}}^{2,0}+\left(\frac{\mathrm{t}_{2}}{2}\right) \psi_{\mathrm{x}}^{2} \\
& \mathrm{u}_{\mathrm{z}}^{1,0}=\mathrm{u}_{\mathrm{z}}^{2,0}
\end{aligned}
$$

Superscripts 1 and 2 of the displacements refer to the upper and lower sublaminates, respectively, and the second superscript 0 refers to the sublaminate's mid-surface. $t_{1}$ and $t_{2}$ are the thicknesses of the upper and lower sublaminates, respectively.

For a delaminated cylinder, the double-layer model can be employed where in areas of delamination the constraint equations will be replaced by contact elements between the corresponding nodes of the upper and lower sublaminates. Contact elements will prevent 
the interpenetration of the nodes of the two cylindrical layers in the delamination zone. Interpenetration would neglect the behaviour of real laminates and result in incorrect estimations of the critical load. In comparison with the three-dimensional finite elements, the double-layer model can effectively reduce the computational time and capacity. However, the disadvantage of the double-layer model is that two layers of shell elements are required for both intact and delaminated regions of the shell.

In order to reduce the computational time and capacity for the same level of accuracy, the alternative is to employ a combined double-layer and single-layer of shell elements. Fig. 3a shows the close-up view of a typical combined FE model which can be used for investigation of effects of delamination on the critical buckling loads of cylindrical shells and panels. The intact regions can be represented by a single layer of shell elements, whereas the delaminated regions can be modelled by upper and lower sublaminates that are connected by contact elements, designated GAP in ABAQUS. For the interface region a modified version of the sublaminate connection method, based on equations 1 , must be employed. Therefore, also the rotations $\left(\psi_{x}, \psi_{y}, \psi_{z}\right)$ of all the nodes of the stacked layers at the transition border are coupled in addition to the displacements $\left(\mathrm{u}_{\mathrm{x}}, \mathrm{u}_{\mathrm{y}}, \mathrm{u}_{\mathrm{z}}\right)$. Thus, the coupling between the mid-surfaces of the sublaminates of the damaged and the mid-surface of the laminate of the intact area is described by the following set of equations,

$$
\begin{aligned}
& \mathrm{u}_{\mathrm{x}}^{1,0}-\left(\frac{\mathrm{t}_{1}}{2}\right) \psi_{\mathrm{x}}^{1}=\mathrm{u}_{\mathrm{x}}^{2,0}+\left(\frac{\mathrm{t}_{2}}{2}\right) \psi_{\mathrm{x}}^{2}=\mathrm{u}_{\mathrm{x}}^{0} \\
& \mathrm{u}_{\mathrm{y}}^{1,0}-\left(\frac{\mathrm{t}_{1}}{2}\right) \psi_{\mathrm{y}}^{1}=\mathrm{u}_{\mathrm{y}}^{2,0}+\left(\frac{\mathrm{t}_{2}}{2}\right) \psi_{\mathrm{y}}^{2}=\mathrm{u}_{\mathrm{y}}^{0} \\
& \mathrm{u}_{\mathrm{z}}^{1,0}=\mathrm{u}_{\mathrm{z}}^{2,0}=\mathrm{u}_{\mathrm{z}}^{0} \\
& \psi_{\mathrm{x}}^{1}=\psi_{\mathrm{x}}^{2}=\psi_{\mathrm{x}}^{0} \\
& \psi_{\mathrm{y}}^{1}=\psi_{\mathrm{y}}^{2}=\psi_{\mathrm{y}}^{0} \\
& \psi_{\mathrm{z}}^{1}=\psi_{\mathrm{z}}^{2}=\psi_{\mathrm{z}}^{0}
\end{aligned}
$$

In a study by Tafreshi and Oswald [12], the combined single-layer and double-layer of shell elements, as explained above, were employed to investigate the global buckling behaviour and local damage propagation of composite flat plates containing embedded 
delaminations. Some of the results were compared with the corresponding experimental results. It was shown that in comparison with the three-dimensional modelling the combined modelling can effectively reduce the computational time and capacity for the same level of accuracy. The following explains the FE modelling, buckling and postbuckling procedures and also the method employed for calculation of the strain energy release rate in this study, respectively.

The selection of the mid-surface as a reference surface in a shell element is due to tradition and the ease of defining bending and shear rigidities. However, for composite laminates with delaminations, it leads to the complexity of using constraint equations (Eq .3) to maintain compatibility of displacements on the delaminated front. The other disadvantage is for use with the virtual crack closure technique for calculation of the strain energy release rate [4]. An alternative method which overcomes these difficulties and also simplifies the mesh generation is to choose the reference surface at an arbitrary position within the shell's thickness. Because according to the first-order, shear deformation theory (Eq.1), the deformation at any position within the thickness direction can be expressed by the deformation at any chosen surface, not necessarily the shell's mid-surface.

Fig.3b shows the close-up view of an FE model which has been used in the present study to investigate the effect of delamination in composite laminated shells under external pressure. As shown, the delaminated surface is chosen as the reference surface for both the intact and delaminated regions. Within the damaged region, nodes are separately defined on the upper and lower sub-laminates although they may have the same coordinates. To avoid interpenetration contact elements are employed between the corresponding nodes of the upper and lower sublaminates. Within the intact and delaminated regions the nodes located on the reference surface are offset from the mid-surfaces of the corresponding shells, either in the positive or negative direction. This can be done using the OFFSET command in ABAQUS for shell elements. To maintain compatibility of displacements on the delaminated front, the nodes of the intact and delaminated regions are tied together to have equal deformations. 
Following the eingenvalue analysis, for calculation of the critical buckling load, the postbuckling analysis has been performed. In simple cases, linear eigenvalue analysis may be sufficient for design evaluation; but if there is concern about material non-linearity, geometric non-linearity prior to buckling, or unstable postbuckling response, a loaddeflection analysis must be performed to investigate the problem further. In such situations more sophisticated analysis techniques are necessary. Arc length methods such as the Riks method available in ABAQUS are global load-control methods that are suitable for global buckling and postbuckling analyses; they do not function well when buckling is localized. Alternatives are to analyze the problem dynamically or to introduce damping. In the dynamic case the strain energy released locally from buckling is transformed into kinetic energy; in the damping case this strain energy is dissipated. To solve a quasistatic problem dynamically is computationally expensive. In the current study the automatic stabilization capability in ABAQUS, which applies volume proportional damping to the structure, is used. It should be noted that the initial small deflection that is necessary to make the structure buckle was established by an imperfection to the original mesh. The applied imperfection rested on an eigenmode buckling analysis of the structure, similar to the method employed in Refs. [12, 17]. The maximum initial perturbation was 5\% of the thickness of the shell.

The virtual crack closure technique ( VCCT) is used to calculate the strain energy release rate (SERR). The nodal forces at the crack front and the displacements behind the crack front are used to calculate SERR [36-37]. Fig. 4 shows a model of a pair of four elements in the upper and lower sublaminates at the delamination front. The crack front is located beneath nodes $c_{j}(j=1,5)$. The components of the SERR for the three modes for a typical element are

$$
\begin{aligned}
& \mathrm{G}_{\mathrm{I}}=\frac{1}{2 \Delta \mathrm{A}}\left\{\mathrm{Z}_{\mathrm{c}_{3}}\left(\mathrm{w}_{\mathrm{a}_{3}}-\mathrm{w}_{\mathrm{A}_{3}}\right)+\mathrm{Z}_{\mathrm{d}_{2}}\left(\mathrm{w}_{\mathrm{b}_{2}}-\mathrm{w}_{\mathrm{B}_{2}}\right)+\frac{1}{2}\left[\mathrm{Z}_{\mathrm{c}_{2}}\left(\mathrm{w}_{\mathrm{a}_{2}}-\mathrm{w}_{\mathrm{A}_{2}}\right)+\mathrm{Z}_{\mathrm{c}_{4}}\left(\mathrm{w}_{\mathrm{a}_{4}}-\mathrm{w}_{\mathrm{A}_{4}}\right)\right]\right\} \\
& \mathrm{G}_{\mathrm{II}}=\frac{1}{2 \Delta \mathrm{A}}\left\{\mathrm{Y}_{\mathrm{c}_{3}}\left(\mathrm{v}_{\mathrm{a}_{3}}-\mathrm{v}_{\mathrm{A}_{3}}\right)+\mathrm{Y}_{\mathrm{d}_{2}}\left(\mathrm{v}_{\mathrm{b}_{2}}-\mathrm{v}_{\mathrm{B}_{2}}\right)+\frac{1}{2}\left[\mathrm{Y}_{\mathrm{c}_{2}}\left(\mathrm{v}_{\mathrm{a}_{2}}-\mathrm{v}_{\mathrm{A}_{2}}\right)+\mathrm{Y}_{\mathrm{c}_{4}}\left(\mathrm{v}_{\mathrm{a}_{4}}-\mathrm{v}_{\mathrm{A}_{4}}\right)\right]\right\} \\
& \mathrm{G}_{\mathrm{III}}=\frac{1}{2 \Delta \mathrm{A}}\left\{\mathrm{X}_{\mathrm{c}_{3}}\left(\mathrm{u}_{\mathrm{a}_{3}}-\mathrm{u}_{\mathrm{A}_{3}}\right)+\mathrm{X}_{\mathrm{d}_{2}}\left(\mathrm{u}_{\mathrm{b}_{2}}-\mathrm{u}_{\mathrm{B}_{2}}\right)+\frac{1}{2}\left[\mathrm{X}_{\mathrm{c}_{2}}\left(\mathrm{u}_{\mathrm{a}_{2}}-\mathrm{u}_{\mathrm{A}_{2}}\right)+\mathrm{X}_{\mathrm{c}_{4}}\left(\mathrm{u}_{\mathrm{a}_{4}}-\mathrm{u}_{\mathrm{A}_{4}}\right)\right]\right\}
\end{aligned}
$$


where $\mathrm{X}, \mathrm{Y}$ and $\mathrm{Z}$ are nodal force components, and $\mathrm{u}, \mathrm{v}$ and $\mathrm{w}$ are nodal displacement components in the $\mathrm{x}, \mathrm{y}$ and $\mathrm{z}$ directions, respectively, and $\Delta \mathrm{A}=\Delta \mathrm{c} \times \Delta \mathrm{L}$. In the above equations, it is assumed that the element sizes ahead of and behind the crack tip are equal.

\section{RESULTS AND DISCUSSION}

An example of a laminated cylindrical shell with longitudinal delamination over the entire length under external pressure, similar to the model employed by Simitses et al [27], is presented here to validate the proposed FE modelling approach. The material used is graphite-epoxy and the cross-ply laminates have the stacking sequence of $\left[90^{\circ} / 0^{\circ} / 90^{\circ}\right]_{10 \mathrm{~T}}$. The cylinder is simply supported at both ends. See Fig. 1b. The dimensions of the shell are such that $\mathrm{L} / \mathrm{R}=6$ and $\mathrm{R} / \mathrm{t}=100$. The lamina engineering constants for the graphite-epoxy composite are shown in Table 1.

The numerical results of variation of critical load with delamination width $(\alpha)$ and delamination thickness (h), calculated using the present method, are compared with those obtained by Simitses et al [27]. See Fig.5-I. The critical loads are normalized with respect to the critical load of an intact cylinder. Figs. 5-Ia and 5-Ic show that for the delamination thicknesses of $h=0.5$ and 0.1 , although Simitses et al [27] did not account for the contact (between delaminated layers during buckling), their results agree reasonably well with the present results. However, Fig. 5-Ib shows that for the delamination thickness of $\mathrm{h}=0.3$, there is a large discrepancy of up to $50 \%$, when considering the effect of contact in the buckling mode.

The significant difference between the present results and those of Simitses et al [27], for the case of $h=0.3$, is obviously due to the material interpenetration at the delaminated layers, when the effect of contact is not considered. To investigate the effect of material interpenetration at the debonded region, four other delaminated cylinders with delamination width of $\alpha=30^{\circ}$ or $60^{\circ}$ and delamination thickness of $h=0.5$ or 0.3 , respectively, were analysed. For these cylinders, the contact elements between the delaminated regions were removed to allow the crack surfaces to overlap. Figs 5-II , 5-III 
show the first buckling mode of these cylinders. Figs 5-II, 5-III also show the first buckling mode of the same cylinders when contact elements are placed between the delaminated layers. It can be observed that for $\mathrm{h}=0.5$, the cylinder mainly buckles in a global mode, with or without having contact elements between the delaminated layers. Therefore, the effect of contact in this case is almost negligible. For $\mathrm{h}=0.3$, when the contact elements are removed, the cylinder mainly buckles locally and there is serious penetration between the delaminated layers. As a result, in this case, the influence of contact turns out to be high. Figs. 5-Iva and 5-IVb compare the first buckling modes of two delaminated cylinders with $\mathrm{h}=0.3$ and $\alpha=180^{\circ}$, with and without having contact elements between the delaminated layers, respectively. This is where the differences between the two solutions are most apparent. The buckling curve for $\mathrm{h}=0.3$ and $0^{\circ}<\alpha<360^{\circ}$, for the case without gap elements, is also included in Fig. 5-Ib. It can be seen that this curve is reasonably close to the buckling curve of Ref. [27].

For $\mathrm{h}=0.1$, the very thin upper delaminated layer tends to buckle independently, and the critical buckling load is very low, whenever considering or ignoring the effect of contact.

It should be noted that Simitses et al [27], in their analytical approach, used a linear bifurcation method. Therefore, their calculated critical loads corresponding to (h) and (1-h) were identical. However, they claimed that for the external pressure case, further investigation was required to verify this. In the present study, the critical loads of the above cylinder are also obtained for the delamination thicknesses of $\mathrm{h}=0.2,0.4,0.6,0.8$ and 0.9. See Fig. $6 a$. The results for the delamination thicknesses of $h=0.1,0.3$ and 0.5 are presented in Fig. 6a as well. Fig. 6b shows the critical loads with respect to the delamination thickness for different values of the delamination width. The following observations are made from this study.

For very small values of the delamination width, the delamination has no significant effect on the critical loads, regardless of the value for (h). As the delamination moves closer to the outer surface, there is a sharp drop in the critical load at a small delamination width. 
This drop in the critical load continues until it reaches a constant value, almost 5-10\% of that of the perfect shell.

The results show that except when the delamination is located near the outer free surface, the lowest critical buckling load occurs for the delamination which is located at the shell's mid-surface. The variations of the critical loads for the delamination thicknesses of $\mathrm{h}=0.3$ and $\mathrm{h}=0.7$ are almost identical. The same variations can be observed for $\mathrm{h}=0.4$ and $\mathrm{h}=0.6$, as predicted by Simitses et al [27]. However, the delamination thickness of $\mathrm{h}=0.9$ gives the highest critical loads as opposed to the predicted results by Simitses et al [27]. For the delamination width of $\alpha<90^{\circ}$ degrees the critical loads for $\mathrm{h}=0.2$ and $\mathrm{h}=0.8$ are almost identical, while there is a large discrepancy for the delamination width of $\alpha>90^{\circ}$ degrees. For a delamination thickness of $h=0.2$ and delamination width of $90^{\circ}<\alpha<225^{\circ}$ degrees, the critical load is almost independent of the delamination width and there is a sharp drop in the critical load for $\alpha>225^{\circ}$.

Some parametric studies are also performed to investigate the effect of material properties. Similar results are obtained for two other composite cylindrical shells made of kevlarepoxy and boron-epoxy laminates. The cylinders have the same geometry and boundary conditions as the cylinder studied earlier. The cross-ply laminates have the stacking sequence of $\left[90^{\circ} / 0^{\circ} / 90^{\circ}\right]_{10 \mathrm{~T}}$. The lamina engineering constants for the kevlar-epoxy and boron-epoxy composites are shown in Table 1. Fig. 7 compares the variations of the critical load with the delamination length and delamination thickness for the graphiteepoxy, kevlar-epoxy and boron-epoxy cylinders. The presented results include the delamination thicknesses of $\mathrm{h}=0.1-0.9$, with the increment of 0.1 . It can be seen that for the selected materials, the trends of the variation of buckling loads with respect to the delamination width are similar. However, for a given delamination size and location there is a slight discrepancy between the critical loads of two cylinders with different material properties. It is observed that in this case the material properties do not have a great influence on the critical buckling load of a delaminated cylinder. 
Next, the effect of the stacking sequence of the laminate is investigated. Here, the above simply-supported graphite-epoxy cylinder, with dimensions of $\mathrm{L} / \mathrm{R}=6$ and $\mathrm{R} / \mathrm{t}=100$ under external pressure and the stacking sequence of $\left[90_{2} / 0 / \pm 45 /-+45 / 0 / 90_{2}\right]_{2 T}$ is analysed. Fig. 8a shows the variation of the critical load with respect to the delamination width $(\alpha)$ for the delamination thicknesses of $\mathrm{h}=0.1-0.9$, with the increment of 0.1 . Fig. $8 \mathrm{~b}$ shows the variation of the critical load with respect to the delamination thickness for different values of the delamination width. By comparing figures 6 and 8, it can be said that the stacking sequence has a great influence on the critical buckling load of the delaminated cylinder. Figs. $8 \mathrm{a}$ and $8 \mathrm{~b}$ also show that for small delamination areas when $\mathrm{h}>0.3$, the delamination has no significant effect on the critical load. For $\mathrm{h}<0.3$ there is a sharp drop in the critical buckling load regardless of the delamination size. For a delamination width of $\alpha>90^{\circ}$ the lower the delamination thickness is the lower the critical buckling load is. When $0.3<\mathrm{h}<0.8$, there is a gradual increase in buckling load with respect to the increase in the delamination thickness. It can be said that for $0.3<\mathrm{h}<0.8$ the delamination thickness does not have a great influence on the critical buckling load.

Next, postbuckling analysis was performed on a graphite-epoxy delaminated cylinder with dimensions of $\mathrm{L} / \mathrm{R}=6$ and $\mathrm{R} / \mathrm{t}=100$ and stacking sequence of $\left[90^{\circ} / 0^{\circ} / 90^{\circ}\right]_{10 T}$. Four different delamination widths, $\alpha=15^{\circ}, 30^{\circ}, 45^{\circ}$ and $60^{\circ}$, respectively, extended over the entire length, with delamination thickness of $\mathrm{h}=0.3$, were considered. The external pressure $(\mathrm{P})$ was increased incrementally up to 1.5 times the critical buckling pressure $\left(\mathrm{P}_{\mathrm{c}}\right)$ of the same cylinder but without any delamination. Fig. 9 illustrates the normalized midpoint out of surface deflections $\left(\mathrm{u}_{\mathrm{z}} / \mathrm{t}\right)$ of the upper sublaminate with respect to the normalized external pressure.

It is observed that for the delamination width of $\alpha=15^{\circ}$, the external pressure can be significantly greater than the critical buckling load of the intact cylinder. For delamination width of $\alpha=45^{\circ}$ and $60^{\circ}$, the evolution of the displacements produced by the applied load is very smooth and does not reflect the early local instabilities in the structure. However, when the global instability develops, the displacements dramatically increase with the increase of the applied pressure, indicating the complete loss of load carrying capacity of 
the structure. The variations of the SERR with normalized applied external pressure, are shown in Fig. 10. An inspection of each model's energy content reveals that for small delamination width while the load is increasing, the amount of energy release rate is negligible. For a larger delamination width, although initially the energy release rate is negligible, as soon as the load reaches a certain amount, the displacement increases dramatically, as does the energy release rate. Obviously, once the energy release rate exceeds the magnitude of the fracture toughness of the material, the delamination growth begins.

It can be concluded that for very small delamination areas, the presence of delamination does not appreciably alter the critical load of a perfect geometry. For large delamination areas, especially as position of delamination moves closer to the free surface of the laminate, the critical load is very small. In this case the critical load is not related to the load carrying capacity of the system and failure will be due to the delamination growth which depends on the fracture toughness of the material. Fig. 11 shows the SERR distribution along the crack front for different loading level of the above cylinder. It can be seen that the highest energy release rate occurs at the middle of the cylinder. This implies that for the laminate the delamination growth would initiate from this point.

Fig. 12 shows the first buckling mode of the intact graphite-epoxy cylindrical shell. Fig. 13 shows the first buckling mode of the delaminated cylinder with delamination width of $\alpha=45$ degrees and delamination thickness of $h=0.3$, extended along the entire length of the cylinder

Depending on the size and through the thickness position of delaminations and also material properties of the cylindrical shell, three different modes of buckling behaviour were observed. The local mode occured when the delamination was near the free surface of the laminate and the area of the delamination was large. The global mode occured when the delamination had a small area and was deeper within the laminate. The mixed mode was a combination of local and global buckling. 
Results are also generated for a cylindrical shell with a rectangular delamination. See Fig.14. The dimensions and boundary conditions of the cylindrical shell are the same as the cylinder studied earlier $(\mathrm{L} / \mathrm{R}=6, \mathrm{R} / \mathrm{t}=100)$. The analysis has been carried out for a graphiteepoxy laminate with the stacking sequence of $\left[90^{\circ} / 0^{\circ} / 90^{\circ}\right]_{10 \mathrm{~T}}$. The results are computed for different delamination sizes and thicknesses. The delamination length $(\overline{\mathrm{a}}=\mathrm{a} / \mathrm{L})$ and delamination width $(\alpha)$ vary as $0.04<\bar{a}<0.42$ and $\pi / 12<\alpha<\pi$, respectively. The delamination thicknesses considered are, $\mathrm{h}=0.1-0.9$, with the increment of 0.1 . For the sake of brevity only the results for $\mathrm{h}=0.1,0.3$ and 0.5 are presented here.

It is observed that for the analysed delamination sizes the critical loads corresponding to (h) and (1-h) were almost identical and the lowest buckling load occured for $h=0.5$. Figs. 14a and $14 \mathrm{~b}$ show the effect of delamination width and delamination length, respectively, on the critical buckling load of the cylinder for $h=0.5$. Fig. $14 \mathrm{c}$ shows the three-dimensional view of the variations of the critical load with respect to the delamination width and delamination length together. It can be seen that for small delamination areas the critical load is almost unaffected by the delamination size. It can also be observed that the critical load is mainly influenced by the delamination length. Therefore, for two models with equal areas of delaminations, the delamination with the higher length creates a lower buckling load. The results for the delamination thicknesses of $h=0.1$ and $h=0.3$ are presented in Fig. 15. These results show that for the delamination sizes considered, when $\mathrm{h}=0.1$, the delamination area has a negligible effect on the critical load.

The number of shell elements, designated S8R in ABAQUS [38], which were used for the modelling of the cylindrical shells throughout this study vary between 2500-4600.

\section{CONCLUDING REMARKS}

Combined single-layer and double-layer of shell elements are employed to study the delamination buckling of composite laminated cylindrical shells subject to external pressure. It is shown that the present method is highly efficient and accurate. Results show that for very small values of the delamination area, the presence of delamination has no 
significant effect on the critical loads. For a large delamination area, especially when the delaminated layer is closer to the free surface of the laminate, the critical load is small. In this case the critical load is not related to the load carrying capacity of the system and failure will be due to the delamination growth which depends on the fracture toughness of the material. It is also observed that ignoring the effect of contact between the delaminated layers can lead to incorrect estimations of the critical buckling loads.

It is also shown that the buckling load was highly influenced by the laminate stacking sequence. It can be said that there are stacking sequences that favour delamination growth and others that exhibit high resistance against the crack extension. Consequently, a laminate can be tailored to delamination growth resistance.

The modelling approach established in this work offers high potential for further development. So far, the material properties were assumed to be linear. However, the structure of the model offers convenient extension to nonlinear behaviour such as friction between the crack surfaces.

\section{REFERENCES}

1. Tafreshi, A., "Shape optimization of anisotropic structures using the boundary element method", Journal of Strain Analysis, 2003; 3, 38, 219-232

2. Tafreshi, A., " Shape design sensitivity analysis of 2D anisotropic structures using the boundary element method", Engineering Analysis with Boundary Elements, 2002; 26, pp237-251

3. Bolotin, V.V., "Delamination in composite structures: its origin, buckling, growth and stability", Composites: Part B, 1996; 27B,129-145

4. T.E.Tay, "Characterization and analysis of delamination fracture in composites: An overview of developments from 1990-2001”, Applied Mechanics Rev., 2003; 56(1): $1-31$ 
5. Klug, J., Wu, X.X. and Sun, C.T., "Efficient modelling of postbuckling delamination growth in composite laminates using plate elements", AIAA J., 1996; 34(1): 178-184

6. Whitcomb, J.D., "Three-dimensional analysis of a postbuckled embedded delamination", Journal of Composite Materials, 1989; 23(9), 862-889

7. Pavier M.J. and Clarke, M.P., "A specialised composite plate element for problems of delamination buckling and growth", Composite Structures, 1996; 34: 43-53

8. Chattopadhyay, A. and Gu, H., "New higher order plate theory in modelling delamination buckling of composite laminates", 1994; AIAA, 32(8): 1709-1716

9. Chai, G.B., Banks, W.M. and Rhodes J., "Experimental study on the buckling and postbuckling of carbon fibre composite panels with and without interply disbonds", Proceedings of the Institution of Mechanical Engineers: Design in Composite Materials, Mechanical Engineering Publications; 1989: 69-85

10. Hu, N.,'Buckling analysis of delaminated laminates with consideration of contact in buckling mode", International Journal For Numerical Methods in Engineering”, 44, 1999, pp1457-1479

11. Chai, H., Babcock, C.A. and Knauss, W.G., "One dimensional modelling of failure in laminated plates by delamination buckling", International Journal of Solids and Structures, 1981; 17(11): 1069-83

12. Tafreshi, A. and Oswald T., "Global buckling behaviour and local damage propagation in composite plates with embedded delaminations", International Journal of Pressure Vessels and Piping, 2003; 80(1): 9-20,

13. Jaunky, N., Knight N.F. Jr, "An assessment of shell theories for buckling of circular cylindrical laminated composite panels loaded in axial compression”, International Journal of Solids and Structures, 1999; 36: 3799-3820

14. Jaunky, N., Knight, N.F. Jr and Ambur, D.R., "Buckling analysis of anisotropic variable-curvature panels and shells", Composite Structures, 1999; 43: 321-329

15. Chaplin, C.P. and Palazotto, A.N., "The collapse of composite cylindrical panels with various thickness using finite element analysis", Computers and Structures, 1996; 60(5): 797-815 
16. Rezeepazhand, J., Simitses, G.J. and Starnes, J.H. Jr, "Scale models for laminated cylindrical shells subjected to axial compression", Composite Structures, 1996; 34: 371-379

17. Tafreshi, A., "Buckling and post-buckling analysis of composite cylindrical shells with cutouts subjected to internal pressure and axial compression loads" International Journal of Pressure Vessels and Piping, 2002; 79(5): 351-359

18. Tafreshi, A.,"Numerical analysis of thin torispherical end closures", International Journal of Pressure Vessels and Piping, 1997; 71: 77-88

19. Tafreshi, A. and Thorpe, T.E., "Effects of local departures from nominal dimensions on stresses in thin torispherical end-closures", Journal of Strain Analysis, 1996; 31(4): 315-324

20. Anastasiadis, J.S., Tabiei, A. and Simitses, G.J. , "Instability of moderately thick, laminated, cylindrical shells under combined axial compression and pressure", Composite structures, 1994; 27: 367-378

21. Shen H.S., "Postbuckling of shear deformable cross-ply laminated cylindrical shells under combined external pressure and axial compression", International Journal of Mechanical Sciences, 2001; 43: 2493-2523

22. Adali, S., Verijenko, V.E. and Richter, A., "Minimum sensitivity design of laminated shells under axial load and external pressure", Composite structures, 2001; 54: 139-142

23. Messager, T., Pyrz, M. Gineste, B. and Chauchot, P., "Optimal laminations of thin underwater composite cylindrical vessels", Composite Structures, 2002; 58: 529-537

24. Xue, J. and Fatt, H., "Buckling of a non-uniform, long cylindrical shell subjected to external hydrostatic pressure", Engineering Structures, 2002; 24: 1027-1034

25. Troshin, V.P., "Effect of longitudinal delamination in a laminar cylindrical shell on the critical external pressure", Journal of Composite Materials., 1983; 17(5): 563567

26. Simitses, G.J. and Chen, Z., "Buckling of delaminated, long, cylindrical panels under pressure", Computers and Structures, 1988; 28(2): 173-184 
27. Simitses, G.J., Chen, Z.Q. and Sallam S., "Delamination buckling of cylindrical laminates", Thin-walled Structures, 1991; 11: 25-41

28. Sallam, S. and Simitses, G.J., "Delamination buckling of cylindrical shells under axial compression", Composite Structures, 1987; 7: 83-101

29. Short,G.J. Guild, F.J. and Pavier,M.J. ,’Delaminations in flat and curved composite laminates subjected to compressive load", Composite Structures, 2002; 58: $249-258$

30. Kutlu, Z. and Chang, F.K., "Composite panels containing multiple through-thewidth delaminations and subjected to compression. Part I: analysis, Composite Structures, 1995; 31: 273-296

31. Kutlu, Z. and Chang, F.K., "Composite panels containing multiple through-thewidth delaminations and subjected to compression. Part II: experiments \& verification, Composite Structures, 31, 1995, pp297-314

32. Naganarayana, B.P., Huang, B.Z. and Atluri S.N., "Multidomain modelling and analysis of delaminated stiffened composite shells", AIAA J., 1996; 34(9):18941904

33. Gu, H. and Chattopadhyay A., "Delamination buckling and postbuckling of composite cylindrical shells", AIAA Journal, 1996; 34(6): 1279-1286

34. Rasheed H.A. and Tassoulas J.L., "Delamination growth in long composite tubes under external pressure", International Journal of Fracture, 2001; 108:1-23

35. Ju-fen Z., Gang, Z., Howson, W.P. and Williams, F.W., "Reference surface element modelling of composite plate/shell delamination buckling and postbuckling”, Composite Structures, 2003; 61 : 255-264

36. Shivakumar, K.N., Tan, P.W. and Newman Jr J.C., "A virtual crack closure technique for calculating stress intensity factors for cracked three dimensional bodies", International Journal of Fracture, 1988; 36: 43-50

37. Raju, I.S. and Shivakumar, K.N., "Three-dimensional elastic analysis of a composite double cantilever beam specimen", AIAA Journal, 1988; 26(12): 14931498

38. ABAQUS User's Manual, Version 6.3, Hibbit, Karlson and Sorenson, Inc. 19992002 

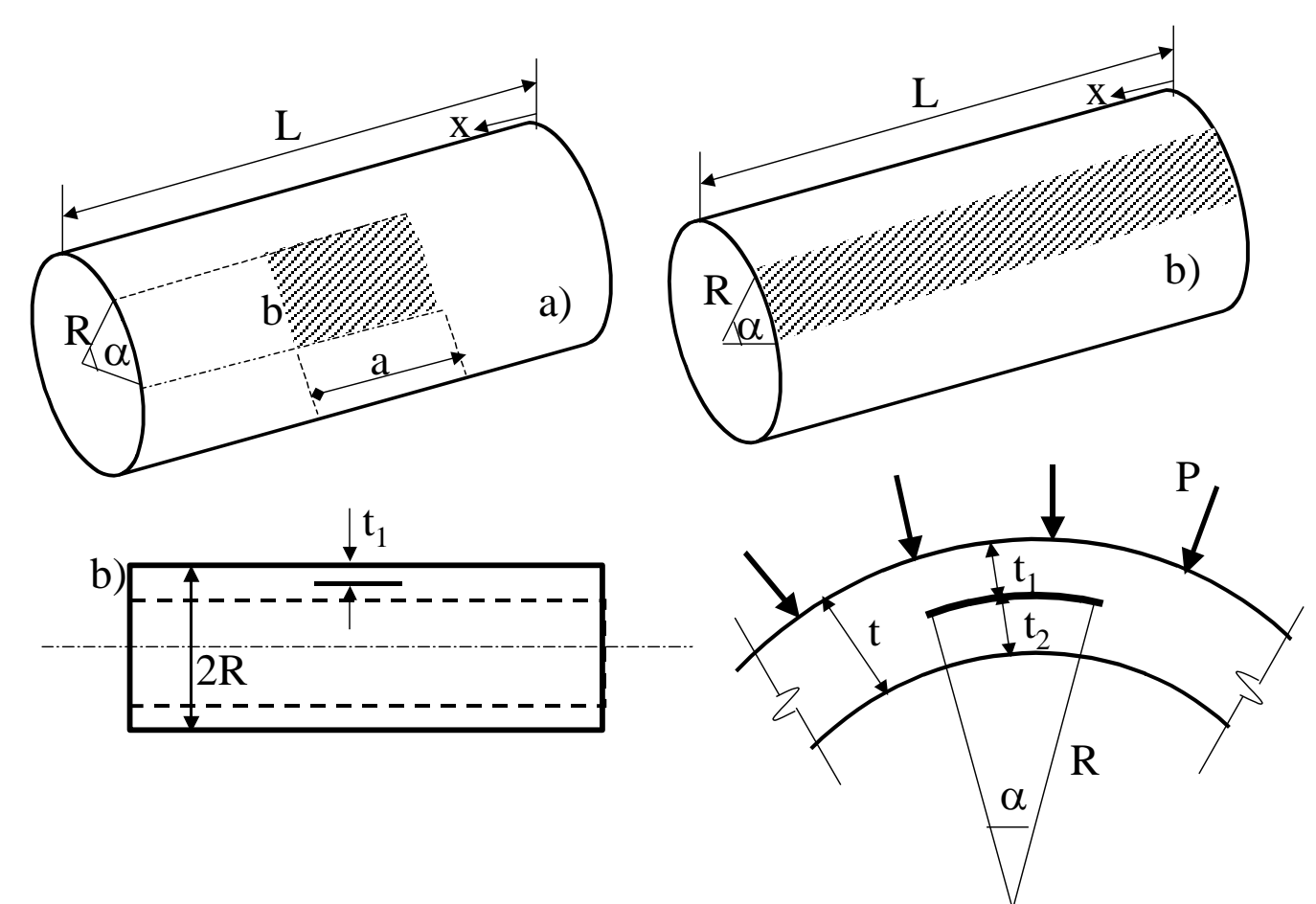

Fig. 1 Geometry of a cylindrical shell under external pressure

a) a rectangular delamination $(a \times b), b=R \alpha$

b) a delamination of width $(\alpha)$, extended along its length

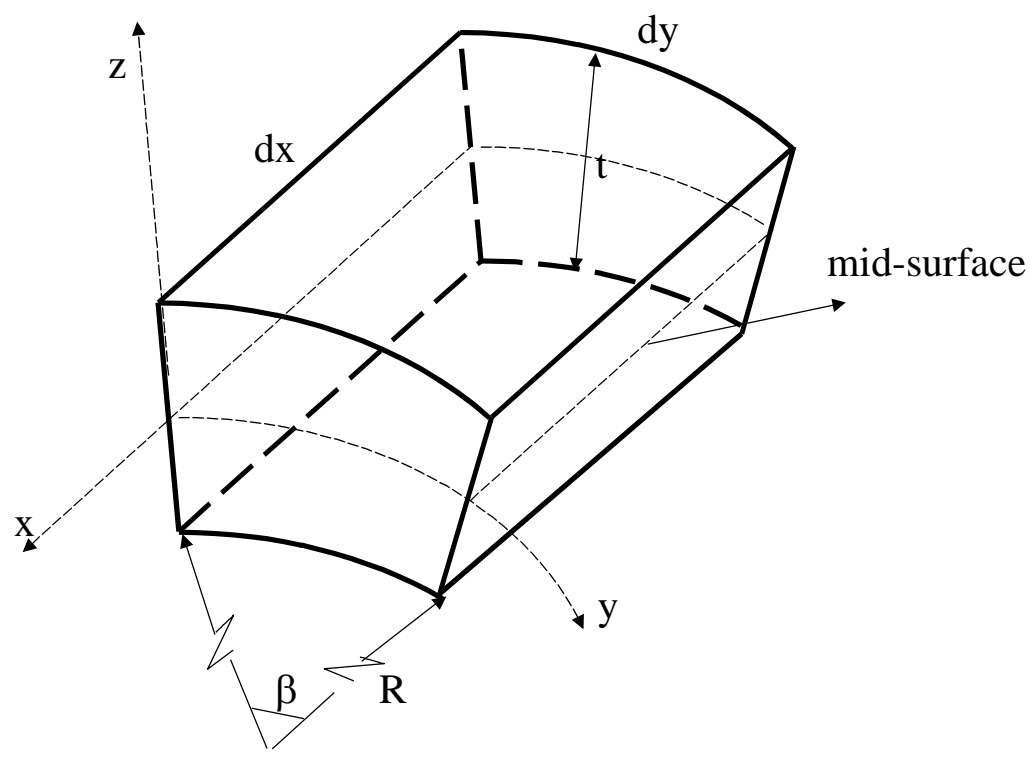

Fig. 2 A cylindrical shell differential element 


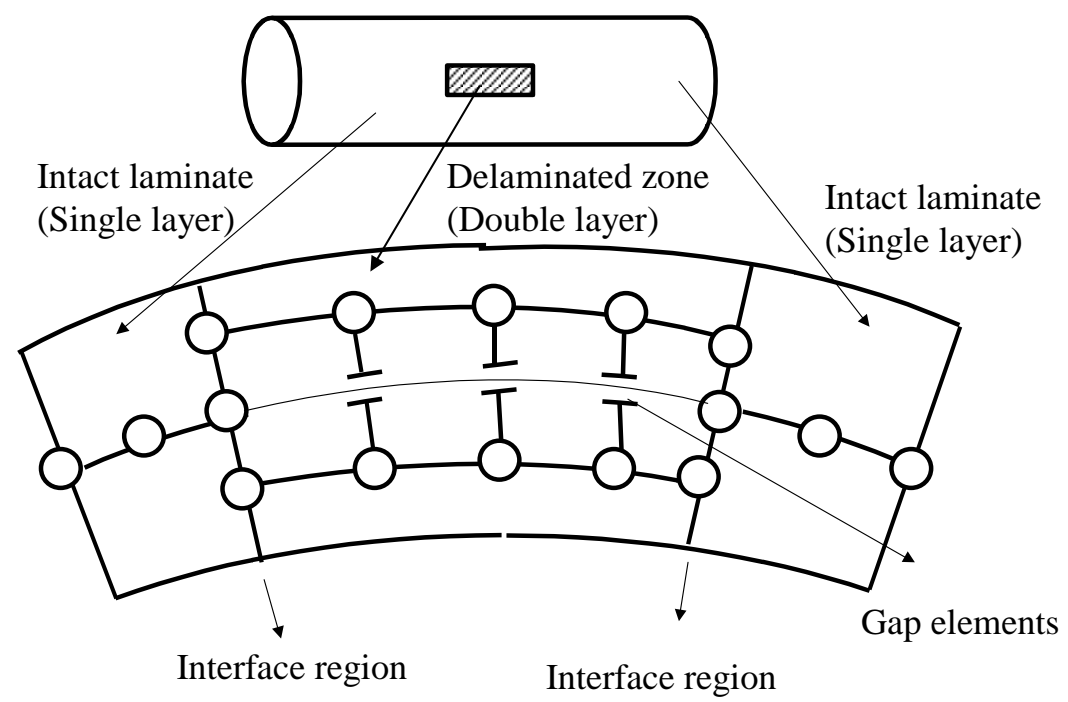

Mid-surface

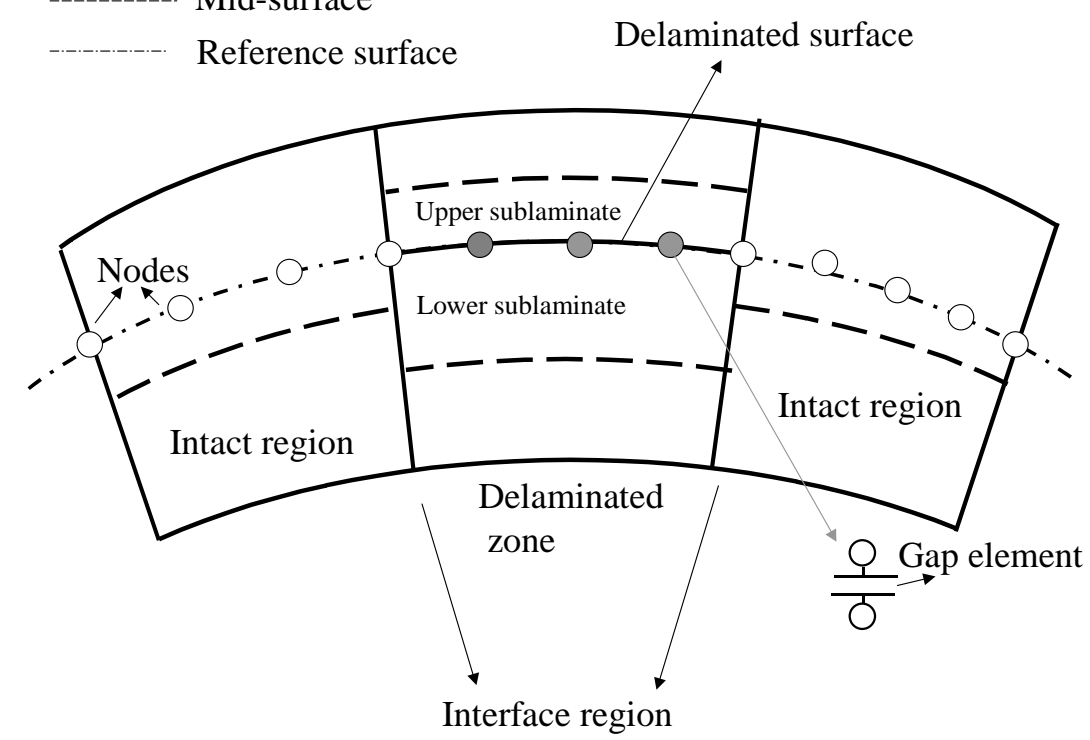

Fig. 3 Close-up view of a typical FE model to be used for study of effect of delamination on the critical buckling load in composite cylindrical shells

a) Nodes are located on the mid-surfaces of the laminate and sublaminates

b) Nodes are located on the reference surface offset from the mid-surfaces of the laminate and sublaminates 


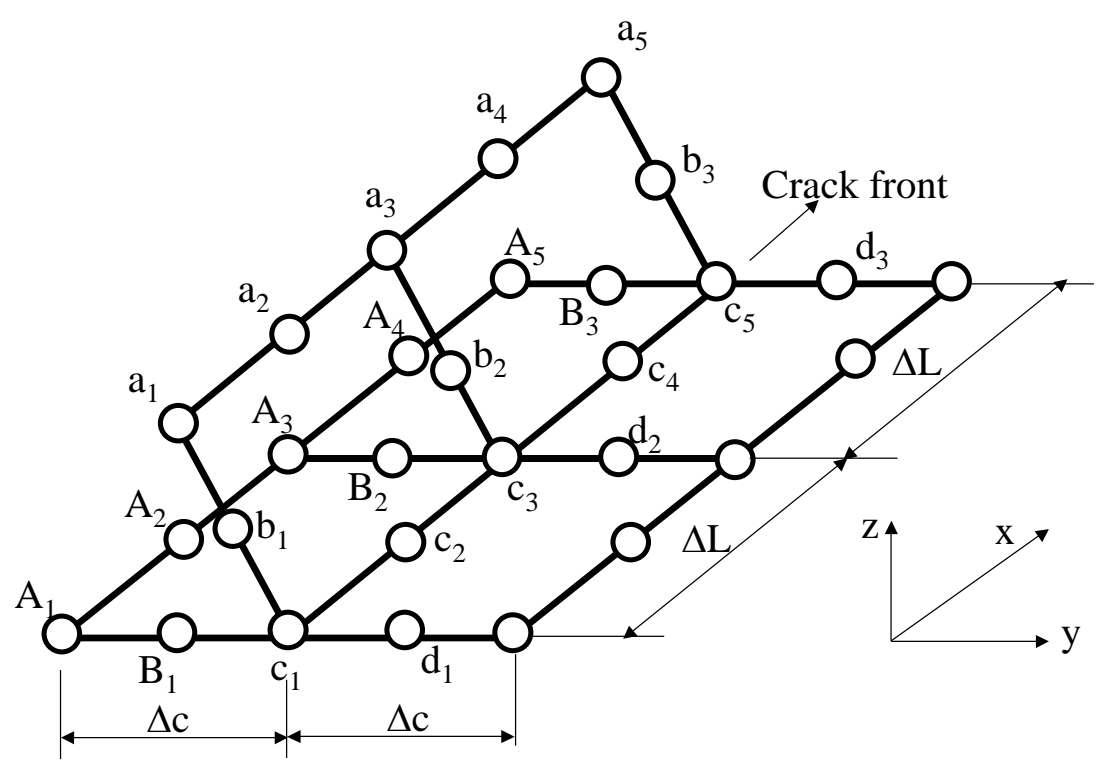

Fig. 4 Schematic of delamination front region 


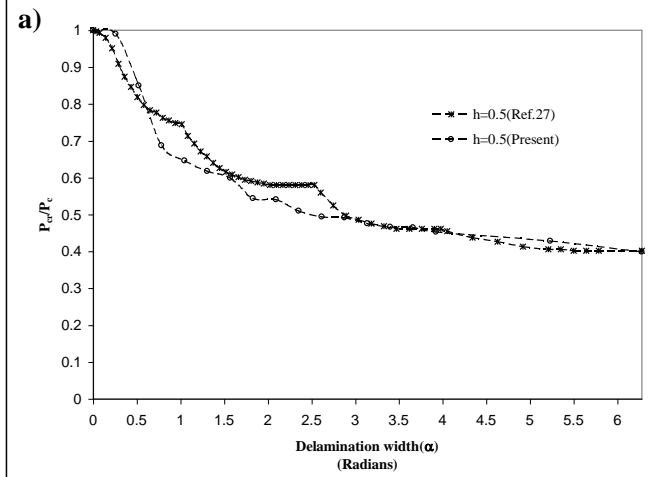

b)

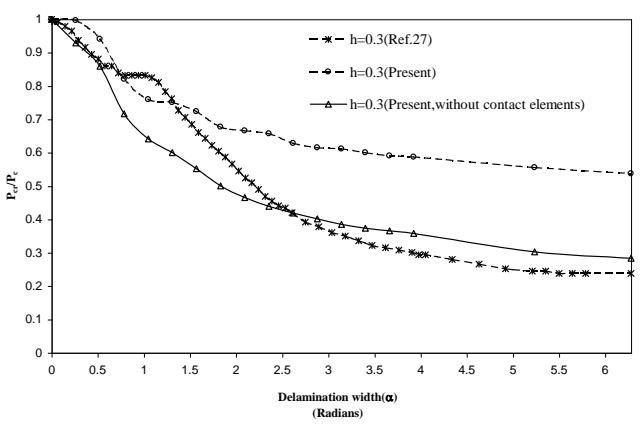

c)
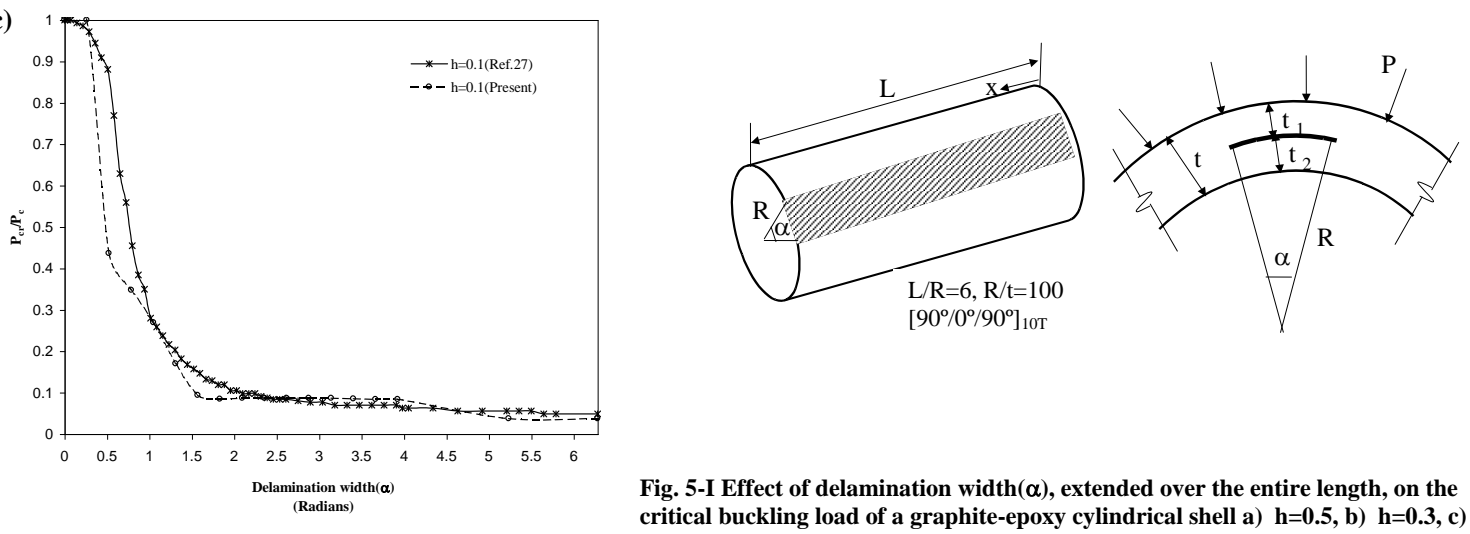

Fig. 5-I Effect of delamination width $(\alpha)$, extended over the entire length, on the critical buckling load of a graphite-epoxy cylindrical shell a) $h=0.5, b) h=0.3, c) h=0.1$ 
a)

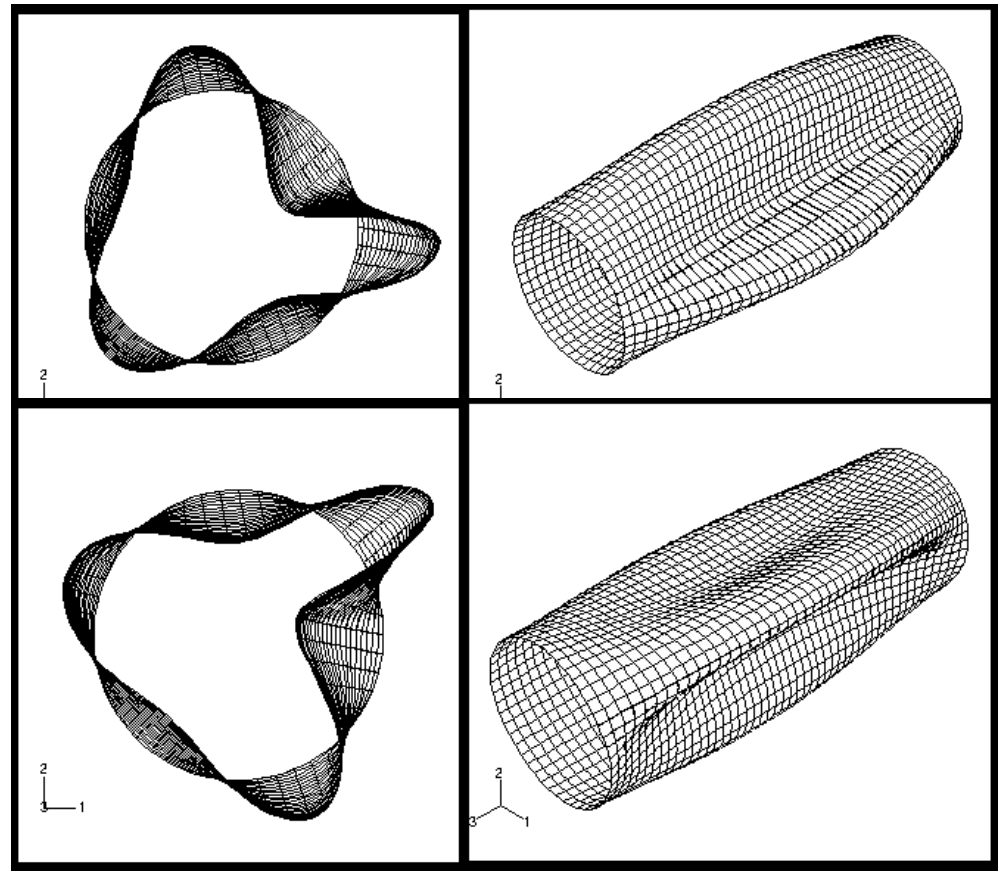

c)

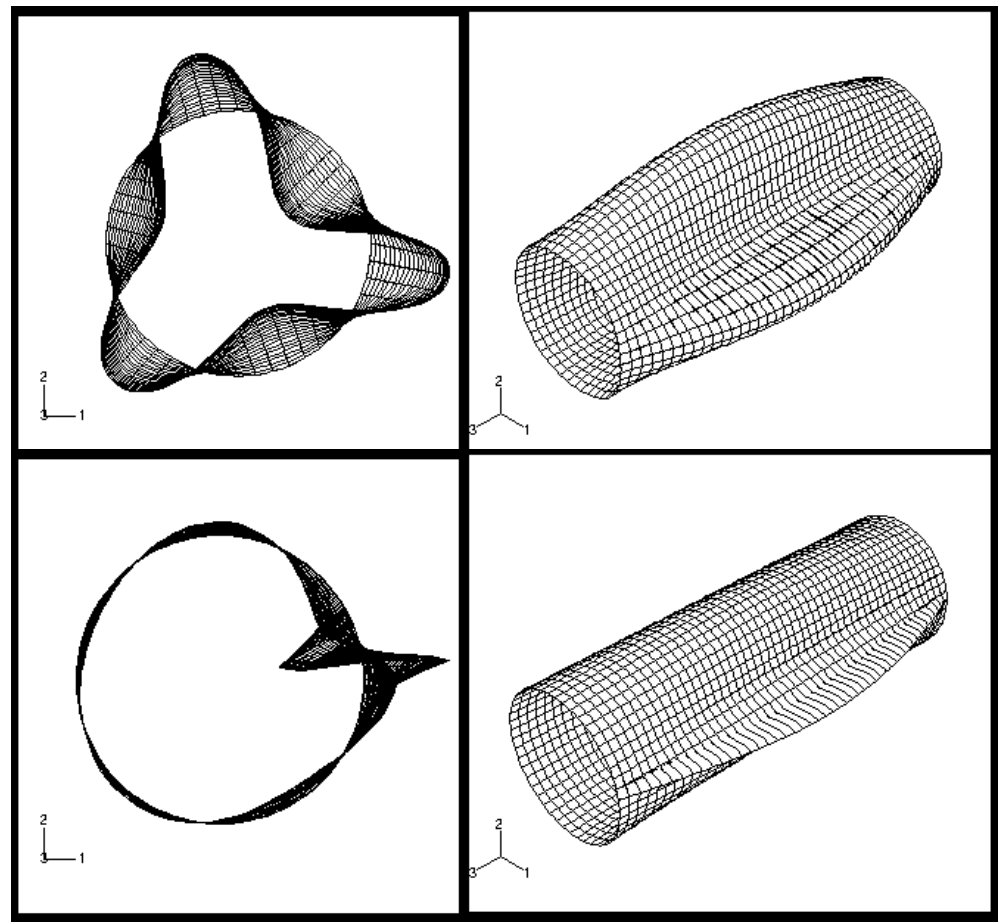

Fig. 5II First buckling mode of a delaminated graphite-epoxy cylindrical $\operatorname{shell}\left(\mathrm{L} / \mathrm{R}=6, \mathrm{R} / \mathrm{t}=100,\left[90^{\circ} / 0^{\circ} / 90^{\circ}\right]_{10 \mathrm{~T}}\right)$ with and without considering the effect of contact
a) $\mathbf{h}=0.5, \alpha=30^{\circ}$ with GAP elements
b) $\mathbf{h}=0.5, \alpha=30^{\circ}$ without GAP elements
c) $h=0.3, \alpha=30^{\circ}$ with GAP elements
d) $h=0.3, \alpha=30^{\circ}$ without GAP elements 
a)

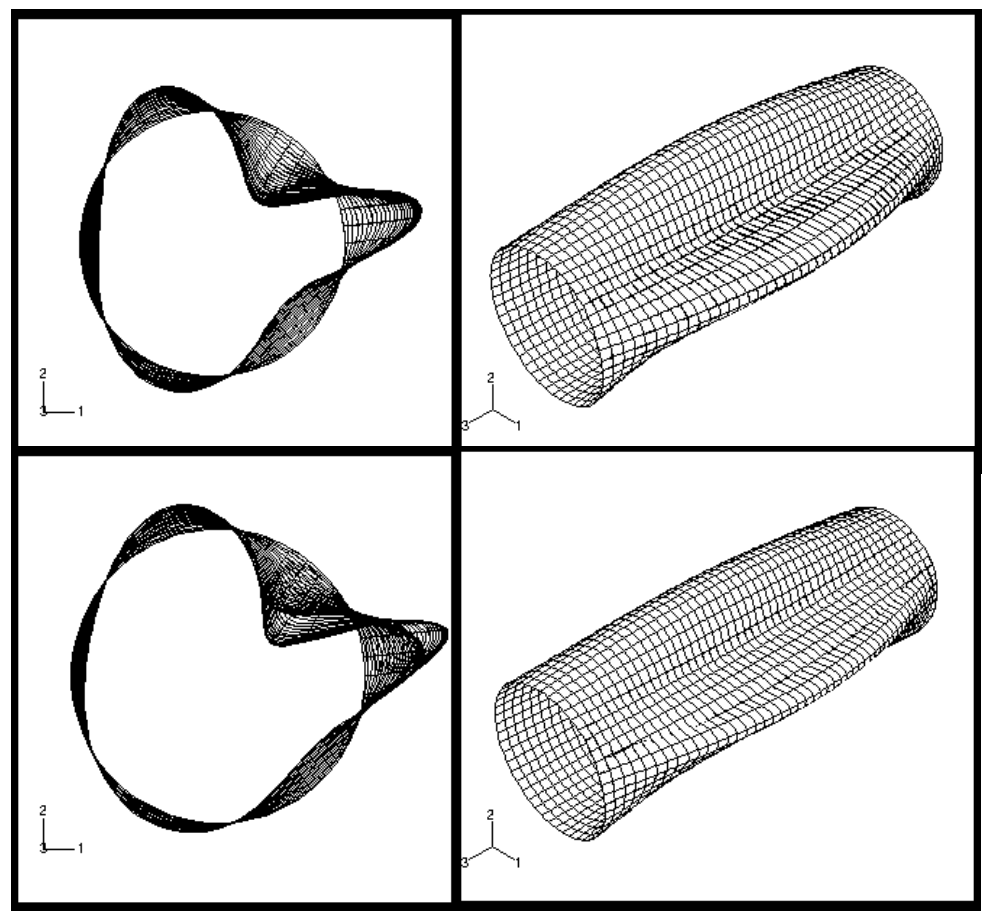

c)

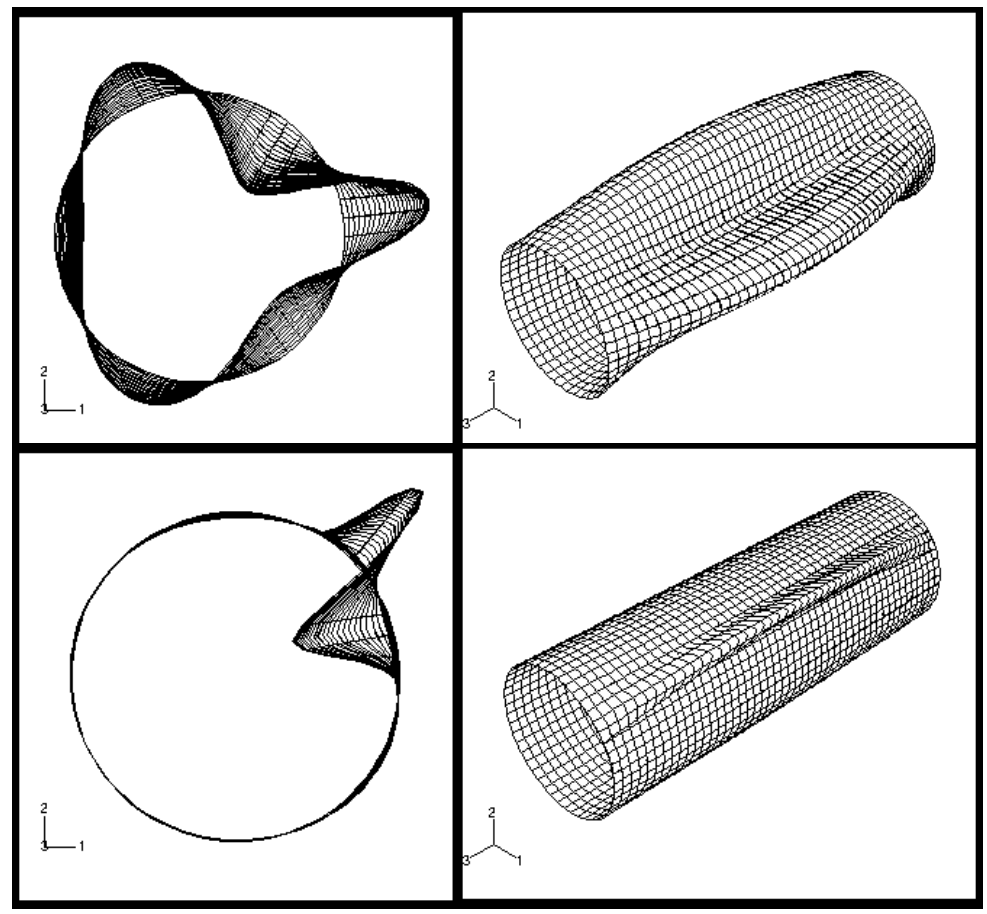

Fig. 5-III First buckling mode of a delaminated graphite-epoxy cylindrical shell $\left(\mathrm{L} / \mathrm{R}=6, \mathrm{R} / \mathrm{t}=100,\left[90^{\circ} / 0^{\circ} / 90^{\circ}\right]_{10 \mathrm{~T}}\right)$ with and without considering the effect of contact
a) $h=0.5, \alpha=60^{\circ}$ with GAP elements
b) $h=0.5, \alpha=60^{\circ}$ without GAP elements
c) $h=0.3, \alpha=60^{\circ}$ with GAP elements
d) $h=0.3, \alpha=60^{\circ}$ without GAP elements 
a)

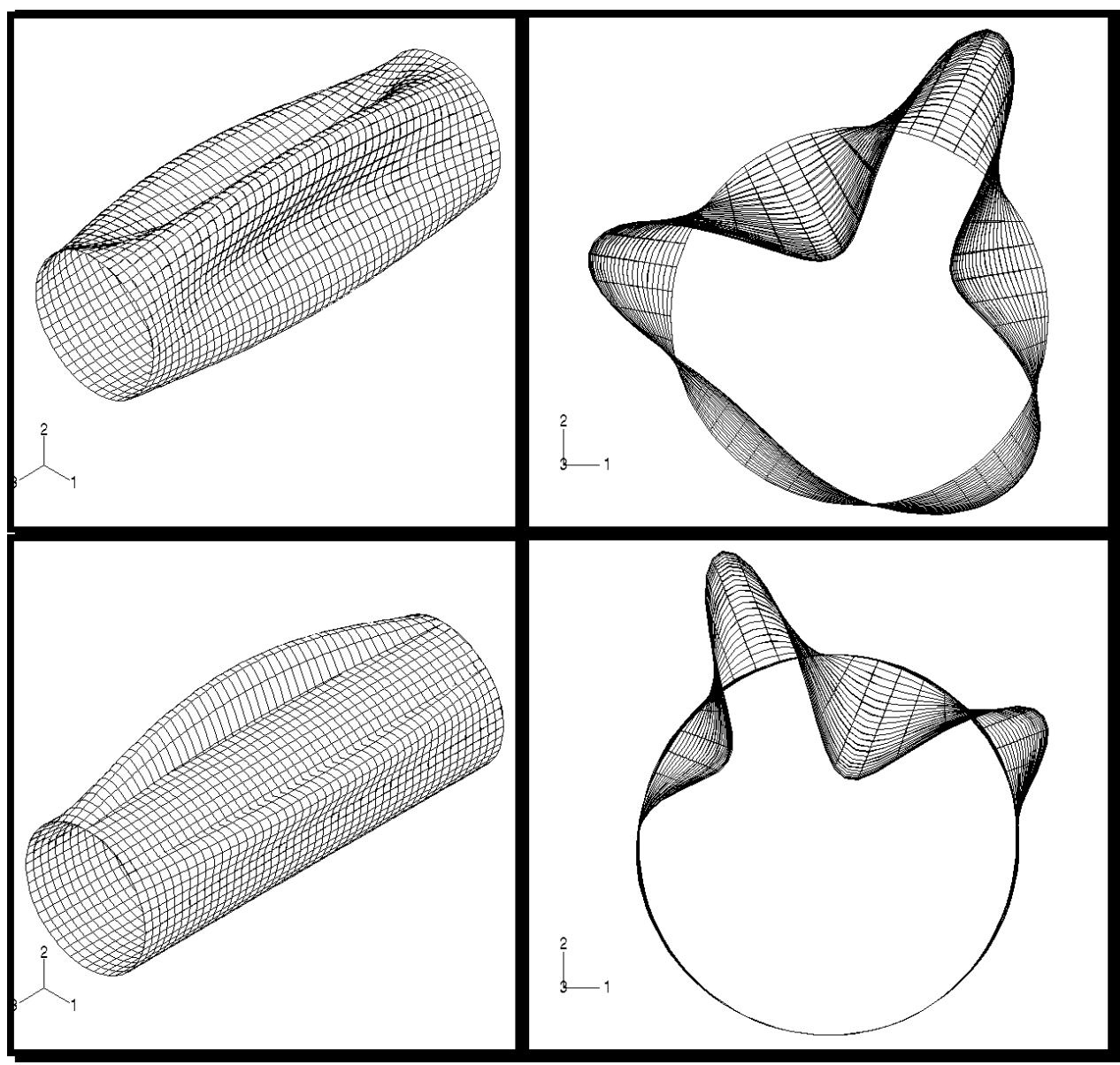

Fig. 5-IV First buckling mode of a delaminated graphite-epoxy cylindrical shell $\left(\mathrm{L} / \mathrm{R}=6, \mathrm{R} / \mathrm{t}=100,\left[90^{\circ} / 0^{\circ} / 90^{\circ}\right]_{10 \mathrm{~T}}\right)$ with and without considering the effect of contact
a) $h=0.3, \alpha=180^{\circ}$ with GAP elements
b) $h=0.3, \alpha=180^{\circ}$ without GAP elements 
a)

$\mathrm{L} / \mathrm{R}=6, \mathrm{R} / \mathrm{t}=100$

$\left[90^{\circ} / 0^{\circ} / 90^{\circ}\right]_{10 \mathrm{~T}}$

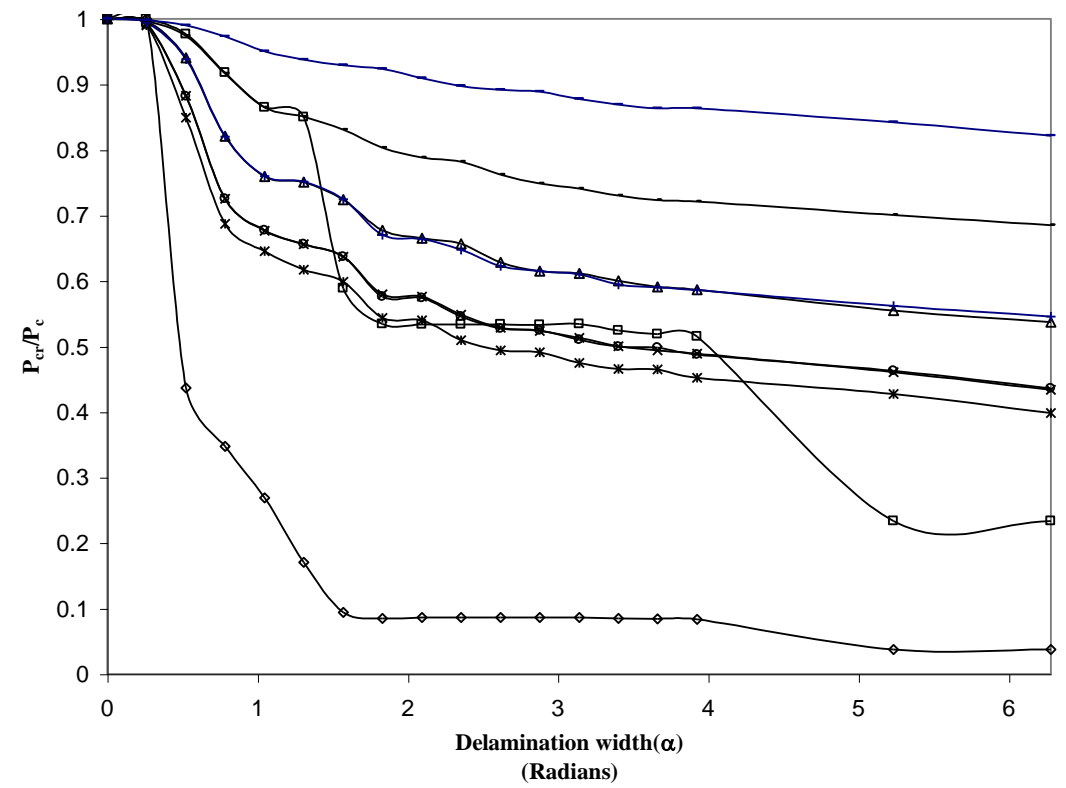

$\rightarrow \mathrm{h}=0.1$

$\square \mathrm{h}=0.2$

$\triangle \mathrm{h}=0.3$

$* \mathrm{~h}=0.4$

$* \mathrm{~h}=0.5$

- $\mathrm{h}=0.6$

— $\mathrm{h}=0.7$

$-\mathrm{h}=0.8$

$\mathrm{h}=0.9$

b)

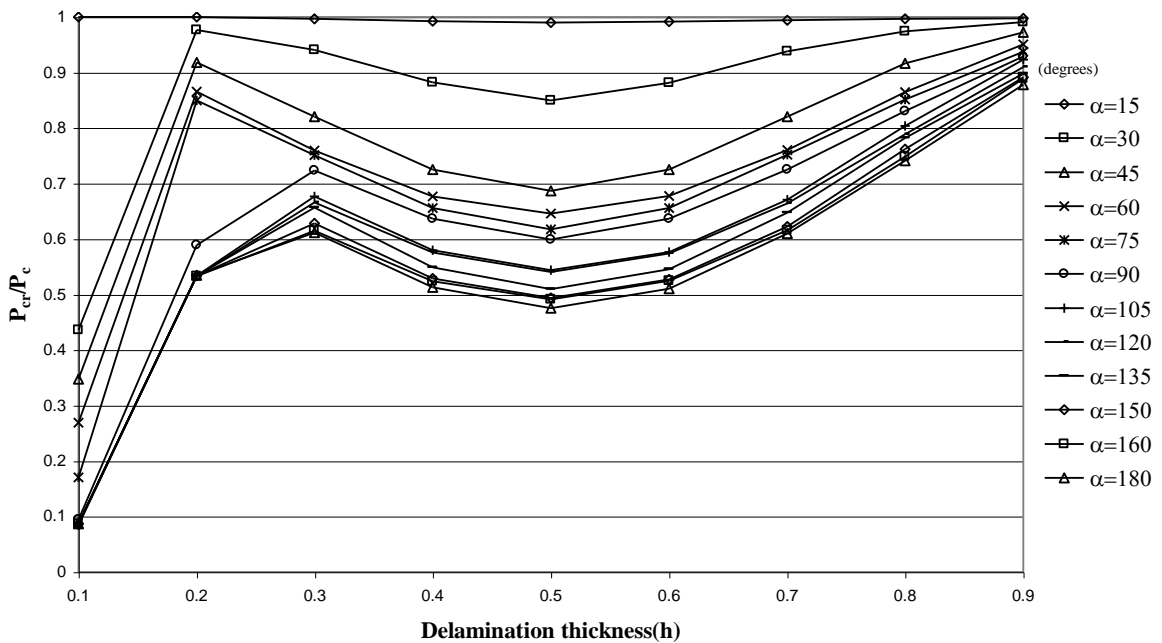

Fig. 6 Effect of delamination width $(\alpha)$ and thickness(h), extended over the entire length, on the critical buckling load of a graphite-epoxy cylindrical shell

a) Critical buckling load vs delamination width $(\alpha)$

b) Critical buckling load vs delamination thickness(h) 
a)

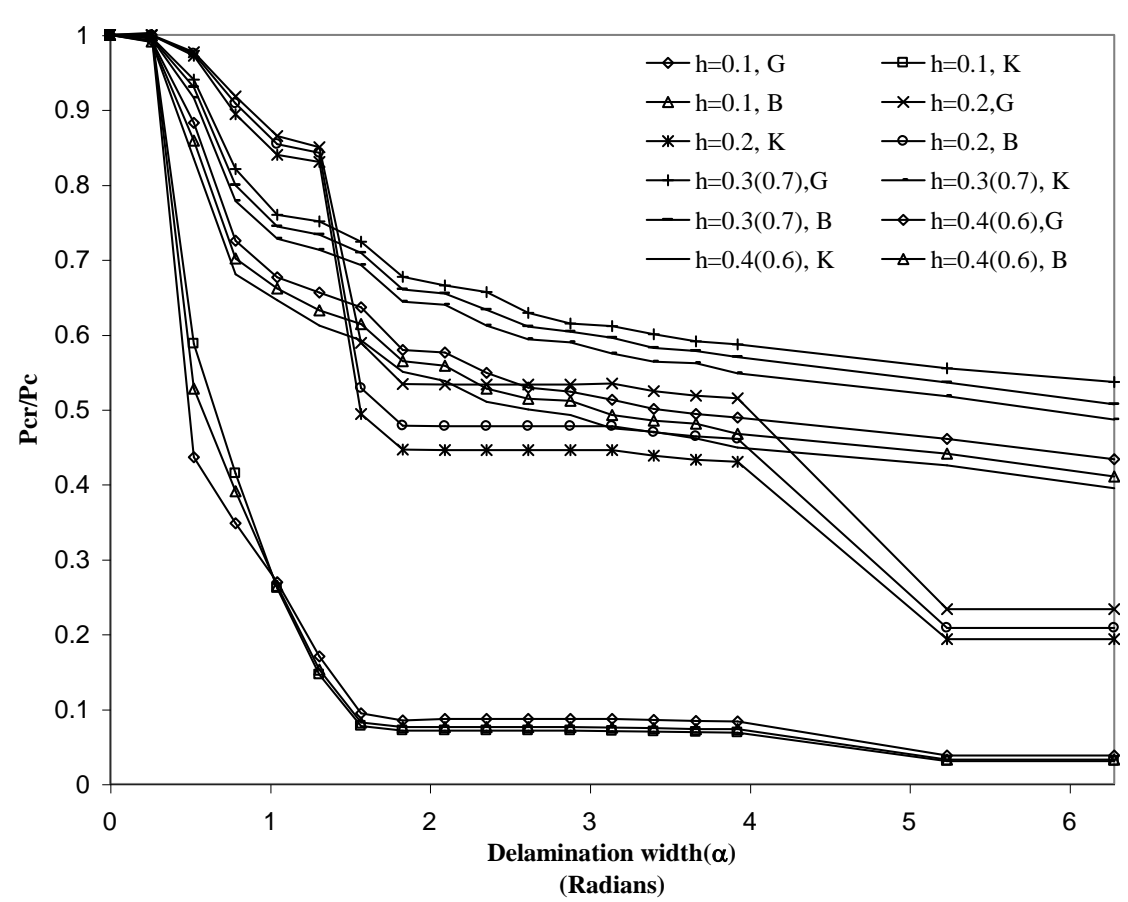

$\mathrm{L} / \mathrm{R}=6, \mathrm{R} / \mathrm{t}=100$

$\left[90^{\circ} / 0^{\circ} / 90^{\circ}\right]_{10 \mathrm{~T}}$

b)

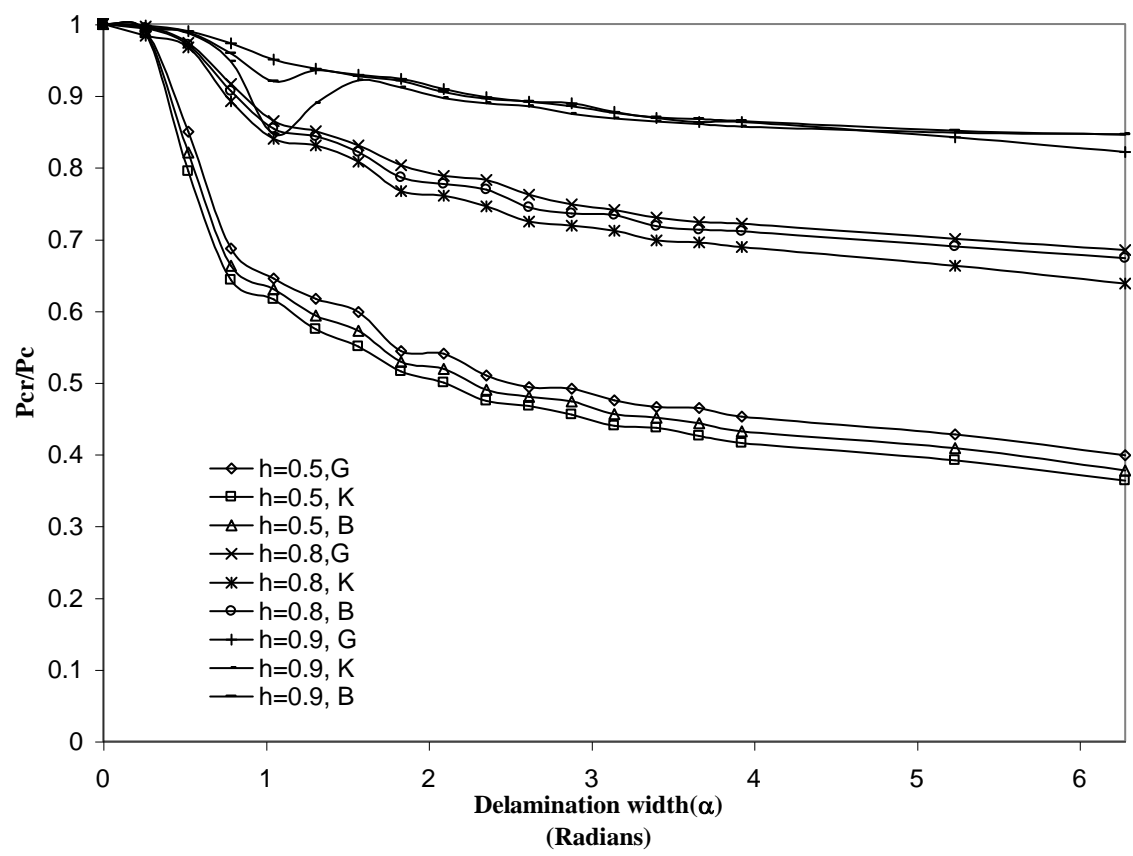

Fig. 7 Effect of delamination width( $\alpha)$ and delamination thickness(h), extended over the entire length, on the critical load with variations in material properties

[G: Graphite-epoxy, K: Kevlar-epoxy, B: Boron-epoxy]

a) $h=0.1,0.2,0.3(0.7)$ and $0.4(0.6)$

b) $h=0.5,0.8$ and 0.9 


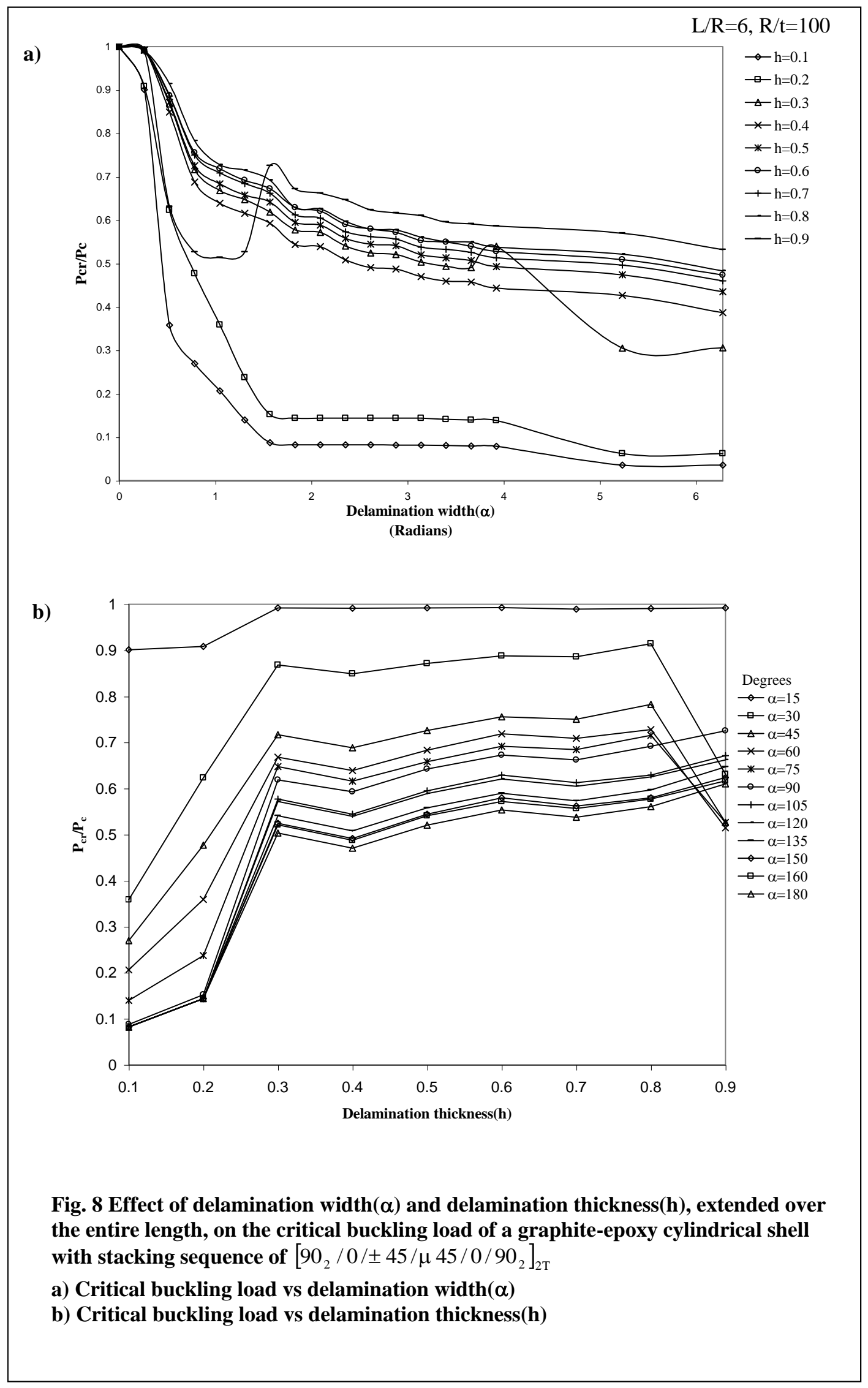


Tafreshi, A. Oct 2004 In : Thin-Walled Structures. 42, 10, p. 1379-1404 26 p.

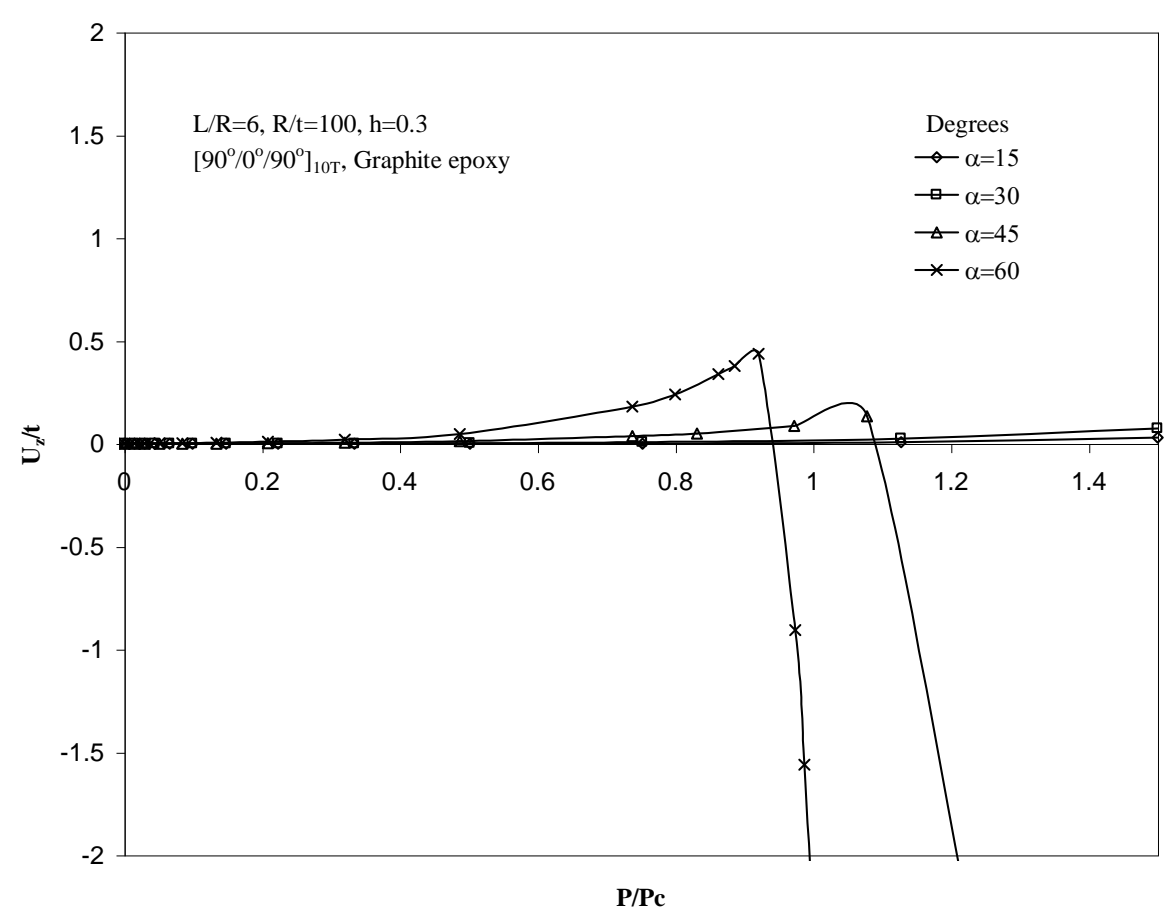

Fig.9 Variation of midpoint out of surface deflection of upper sublaminate with external pressure for different delamination widths

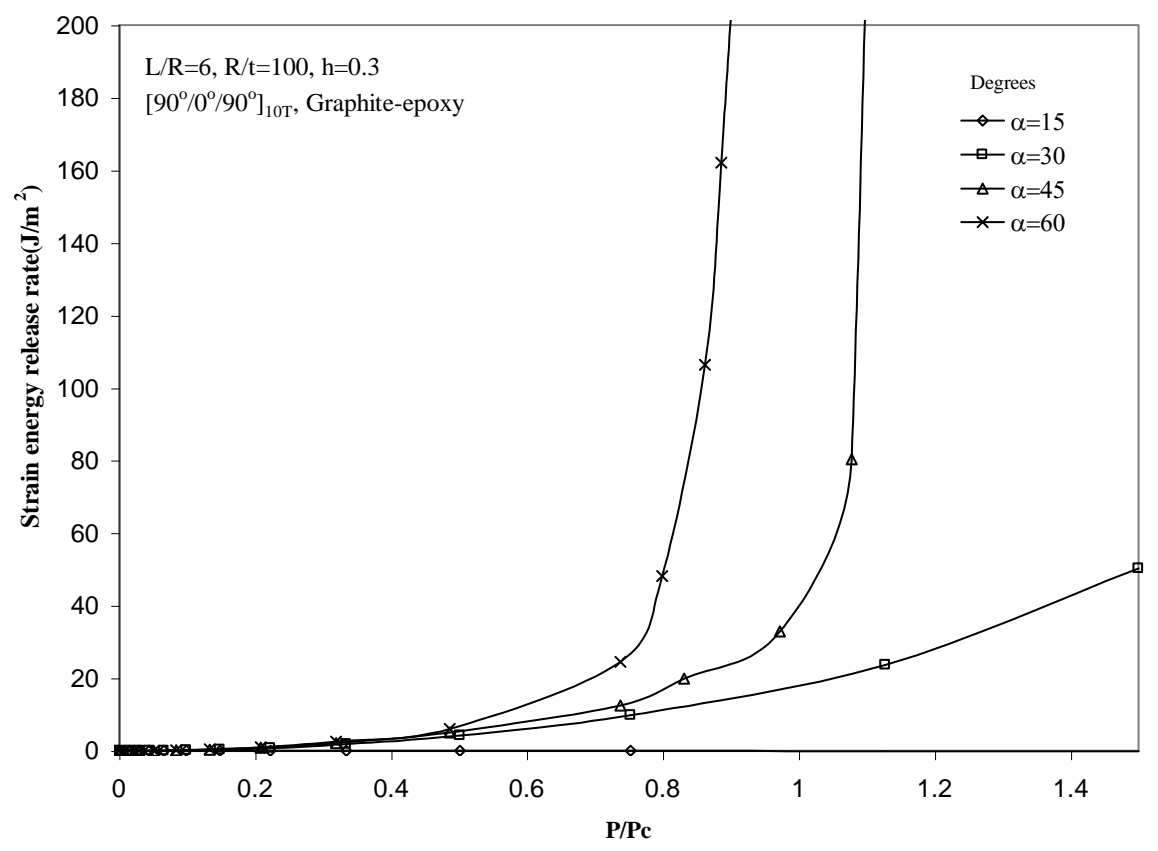

Fig. 10 Variation of maximum energy release rate with external pressure for different delamination widths 
Tafreshi, A. Oct 2004 In : Thin-Walled Structures. 42, 10, p. 1379-1404 26 p.

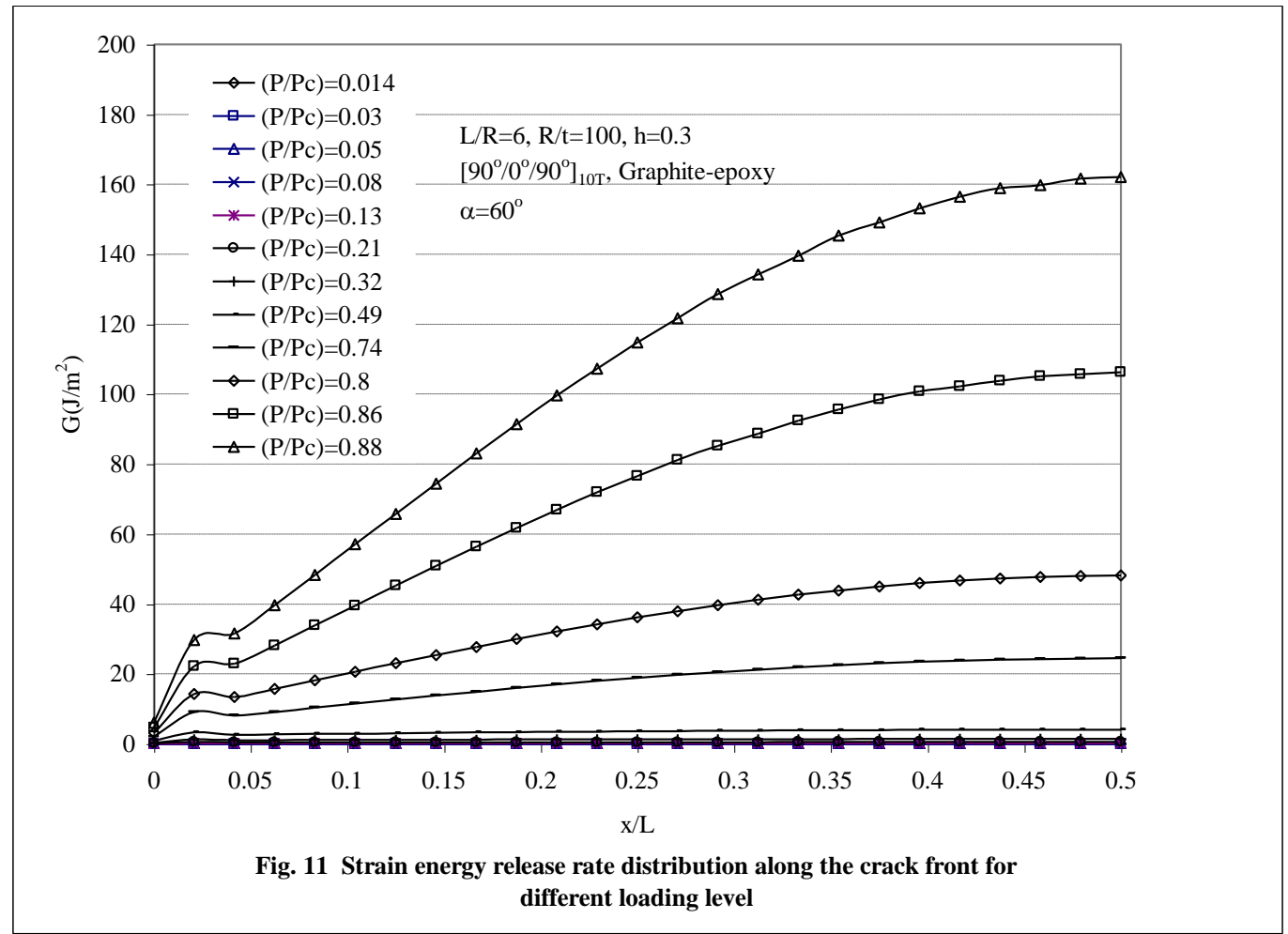




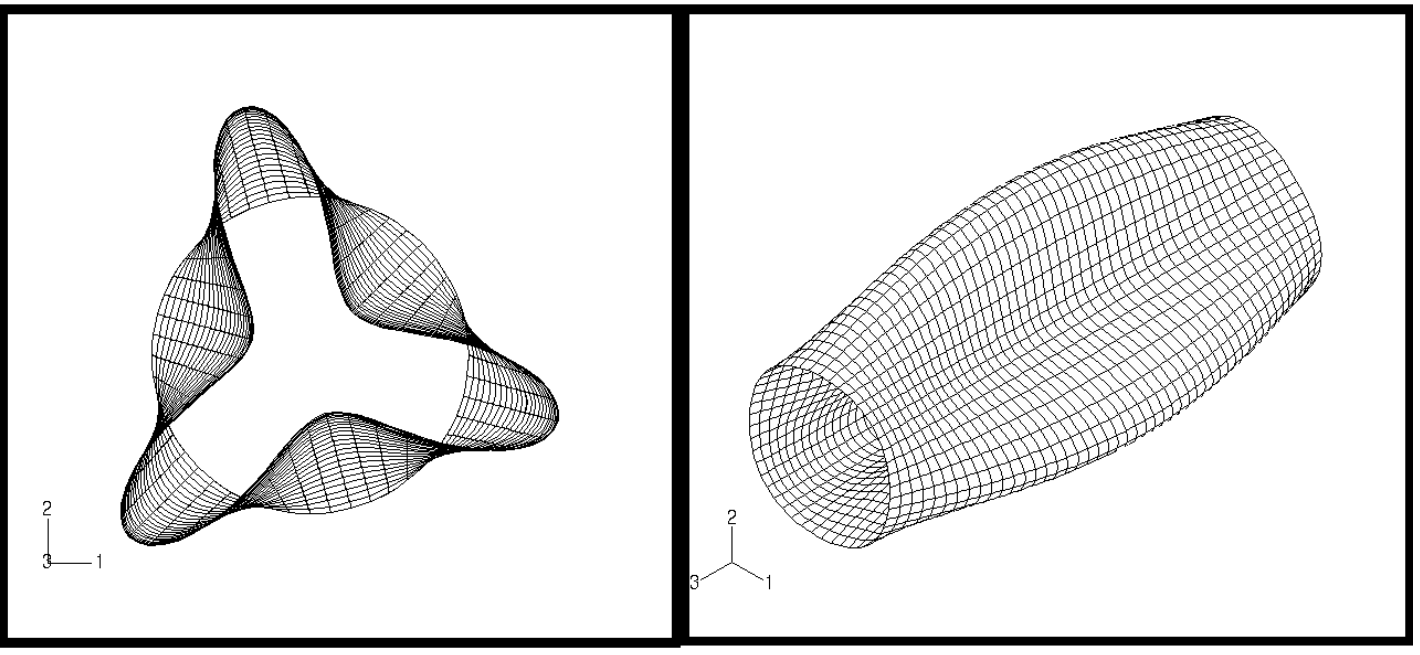

Fig. 12 First buckling mode of an intact graphite-epoxy cylindrical shell $\left(\mathrm{L} / \mathrm{R}=6, \mathrm{R} / \mathrm{t}=100,\left[90^{\circ} / 0^{\circ} / 90^{\circ}\right]_{10 \mathrm{~T}}\right)$

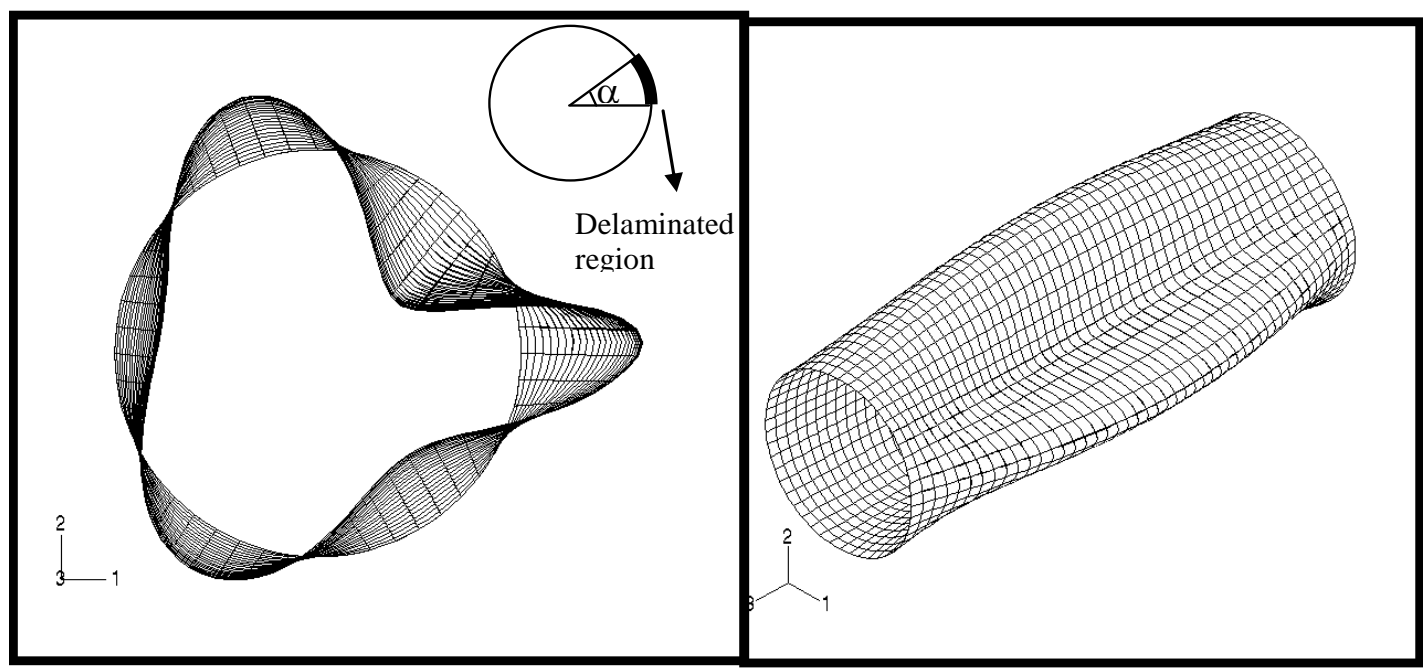

Fig. 13 First buckling mode of a delaminated graphite-epoxy cylindrical shell with delamination width of $\alpha=45^{\circ}$ (extended along the entire length)

$\left(\mathrm{L} / \mathrm{R}=6, \mathrm{R} / \mathrm{t}=100, \mathrm{~h}=0.3,\left[90^{\circ} / 0^{\circ} / 90^{\circ}\right]_{10 \mathrm{~T}}\right)$ 
a)

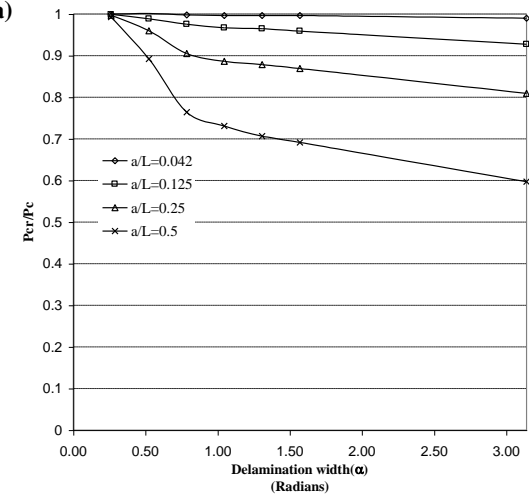

c)

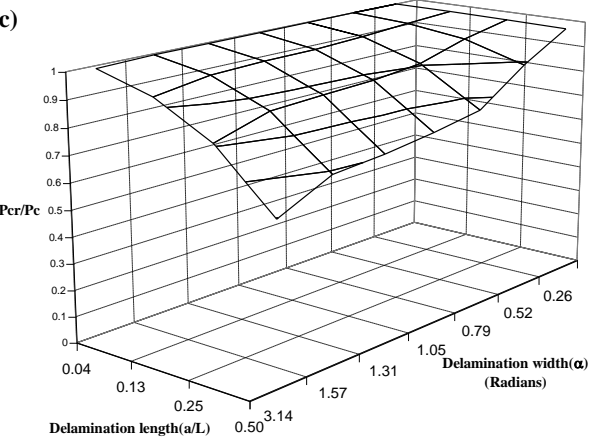

b)
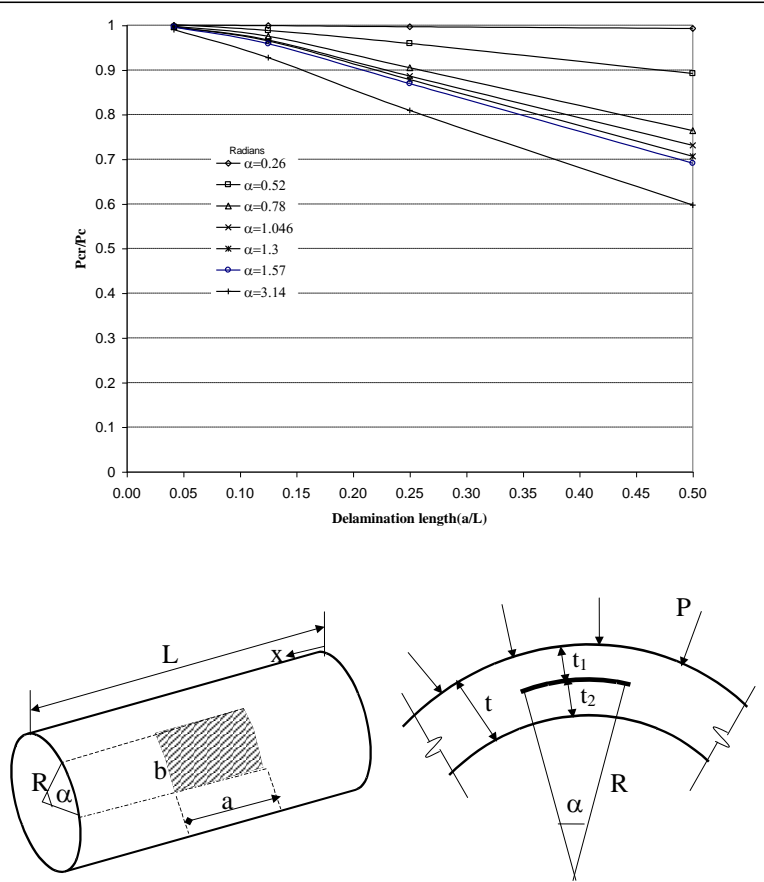

Fig. 14 Effect of delamination size on the critical buckling load of a graphite-epoxy cylindrical shell with a rectangular delamination $\left(\mathrm{L} / \mathrm{R}=6, \mathrm{R} / \mathrm{t}=100, \mathrm{~h}=0.5,\left[90^{\circ} / 0^{\circ} / 90^{\circ}\right]_{10 \mathrm{~T}}\right)$ 
a)

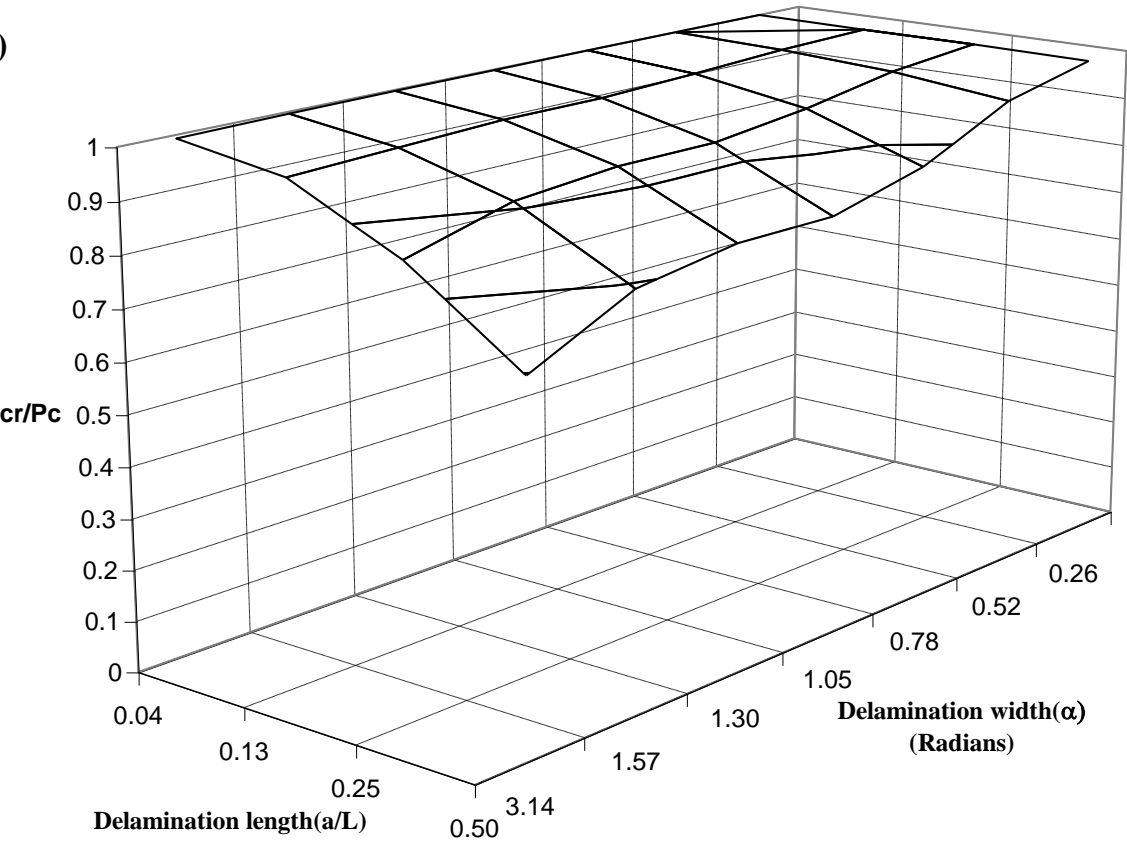

b)

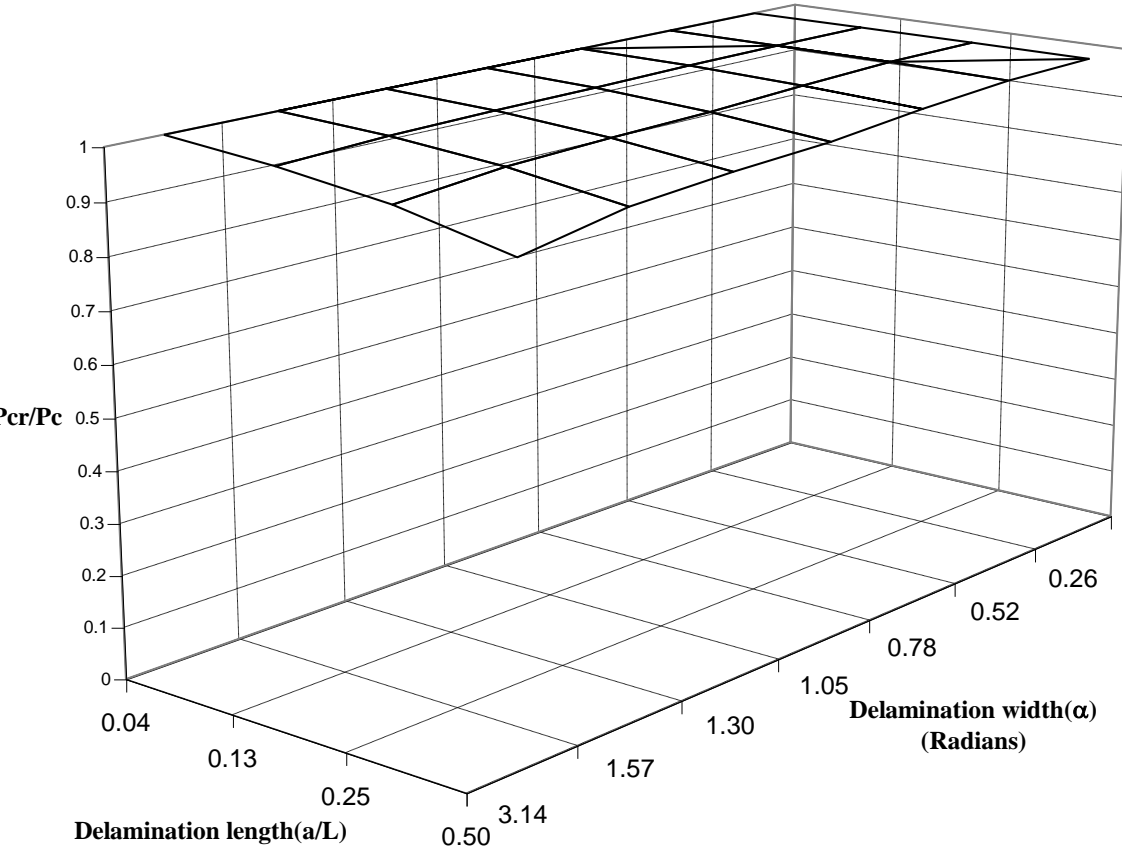

Fig. 15 Effects of delamination width and delamination thickness on critical loads of a graphite-epoxy cylindrical shell with a rectangular delamination , $\left(\mathrm{L} / \mathrm{R}=6, \mathrm{R} / \mathrm{t}=100,\left[90^{\circ} / 0^{\circ} / 90^{\circ}\right]_{10 \mathrm{~T}}\right)$ a) $\left.\mathrm{h}=0.3, \mathrm{~b}\right) \mathrm{h}=0.1$ 